Check for updates

Cite this: Chem. Commun., 2020, 56,12090

Received 1st June 2020

Accepted 27th August 2020

DOI: $10.1039 / \mathrm{d} 0 \mathrm{cc} 03850 \mathrm{~d}$

rsc.li/chemcomm

\section{Metal phosphonates incorporating metalloligands: assembly, structures and properties}

\begin{abstract}
Song-Song Bao, Ming-Feng Qin and Li-Min Zheng (D)*
Metal phosphonates are an important class of metal-organic hybrid materials that exhibit versatile structures, intriguing functions and high water and thermal stability. Despite a large number of metal phosphonates achieved over the past few decades, those incorporating metalloligands are rather limited. The metalloligand approach can provide a unique opportunity in constructing homo- or mixed-metal coordination polymers with rationally immobilized functional moieties for various applications in gas storage and separation, heterogeneous catalysis, sensing and multifunctional materials. In this feature article, we shall introduce the current status of a special subclass of metal phosphonates, namely, metal-metalloligand phosphonates (MMPs), including synthetic strategies, crystal structures, and properties of those based on paddlewheel diruthenium, metallo-polyazamacrocycle, metalloporphyrin and metallo-tris-bipyridine ligands. Future challenges in this field are discussed.
\end{abstract}

\section{Introduction}

Metal-organic hybrid materials, in particular metal-organic frameworks (MOFs), have been developed explosively over the past few decades. ${ }^{1-3}$ These materials are commonly constructed by a combination of metal-containing nodes and organic linkers, wherein a large number of organic linkers with different shapes have been designed and synthesized. Aside from enormous efforts devoted to homometallic MOFs with beautiful structures and

State Key Laboratory of Coordination Chemistry, School of Chemistry and Chemical Engineering, Collaborative Innovation Centre of Advanced Microstructures, Nanjing University, Nanjing 210023, China. E-mail: lmzheng@nju.edu.cn fascinating properties, heterometallic systems containing metalloligands have attracted more and more attention. Metalloligands are defined as metal complexes with appended functional groups that are able to coordinate with second metal ions. Within the context of the metalloligand approach, it is possible to place the auxiliary functional groups in a pre-organized conformation. ${ }^{4}$ Hence this approach offers opportunities to rationally immobilize functionalized or catalytically active metal sites within the frameworks. As a result, enhanced performance in gas storage and separation, heterogeneous catalysis, sensing, or multifunction can be achieved in metal-metalloligand systems. ${ }^{5}$

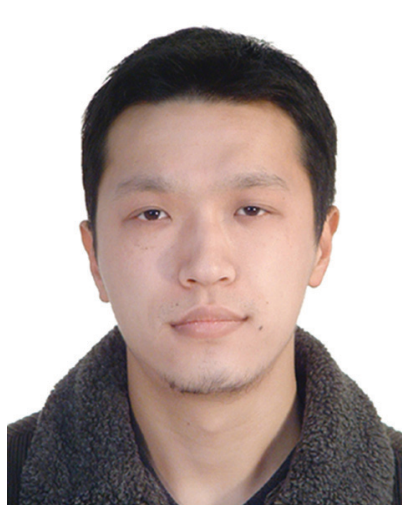

Song-Song Bao
Song-Song Bao completed his PhD degree at Nanjing University in 2008 under the supervision of Prof. Li-Min Zheng. He then studied at Goethe University Frankfurt as a Post-Doctoral Research Associate in the research group of Prof. Matthias Wagner. $\mathrm{He}$ is currently working as associate professor at the School of Chemistry and Chemical Engineering, Nanjing University. His current interests involve the design and synthesis of multifunctional metal phosphonates by using the metalloligand approach.

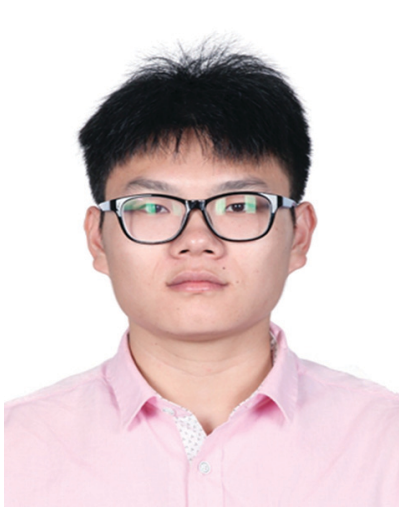

Ming-Feng Qin
Ming-Feng Qin received his bachelor's degree and master's degree from Jiangsu University in 2015 and 2018, respectively. He is currently working on his PhD under the supervision of Prof. Li-Min Zheng at the School of Chemistry and Chemical Engineering at Nanjing University. His current research interests focus on photocatalytic properties of metal phosphonates containing metalloligands. 
Metal phosphonates are an important class of metal-organic hybrid materials, showing promising applications in ionexchange and sorption, catalysis, and materials science. ${ }^{6}$ Compared with many other metal-organic systems, metal phosphonates often show high water and thermal stability, ${ }^{7,8}$ attributed to the presence of inorganic components in the structure such as clusters, chains or layers. The organic moieties of the phosphonate ligands $\mathrm{RPO}_{3}{ }^{2-}$ can be modified by other functional groups resulting in a number of metal phosphonates with versatile structures and functions. For more information, the interested reader is directed to a book which covers most aspects of this field, ${ }^{9}$ and several review articles concerned with the synthesis and structures, ${ }^{10}$ optical, ${ }^{11}$ magnetic, ${ }^{12}$ and proton conductive properties, ${ }^{13}$ as well as their application in catalysis, adsorption, energy storage, drug delivery, etc. ${ }^{14}$ In contrast to the rapid progress of metal phosphonate chemistry, utilization of metalloligands in synthesis has not been well explored. The incorporation of metalloligands in metal phosphonates can not only confer additional function to the material but also provide possibilities to tune the properties through different metal components. However, the number of known metal-metalloligand phosphonates (MMPs) are rather limited. The obstacle could arise from the synthetic challenges in isolating phosphonate-based metalloligands, and the fast precipitation of the MMP products leading to the difficulties in analysing their structures using the conventional single crystal determination method. To solve the structures of MMPs with extremely small crystal sizes, Rietveld refinement using powder X-ray diffraction data as well as singlecrystal electron diffraction method has been employed. ${ }^{15}$

In this feature article, we shall introduce the current status of metal phosphonates incorporating metalloligands including the general synthetic strategies, crystal structures and properties. It is worth mentioning that the metalloligands discussed herein are restricted to those with pendant phosphonate groups such that each phosphonate group can provide at least

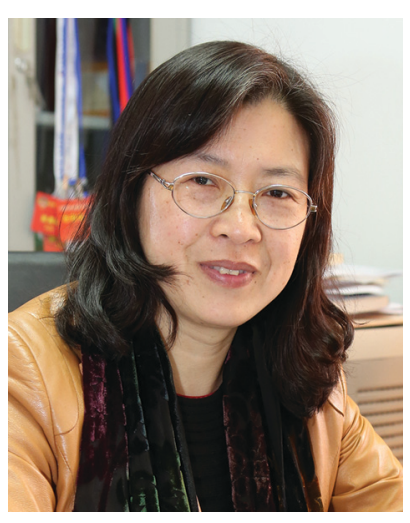

Li-Min Zheng
Li-Min Zheng received her PhD degree from Nanjing University in 1992 under the guidance of Prof. Xinquan Xin. Then she became a lecturer (1992-1997), associate professor (1997-2002) and professor (2002-) at the same University. She spent two years with Prof. Silvio Decurtins as a postdoctoral fellow at the University of Zurich (1994-1996) and one year with Prof. Allan J. Jacobson at the University of Houston (1999-2000). Her research group seeks to develop new crystalline and lowdimensional materials based on metal phosphonates with interesting physical and chemical properties.

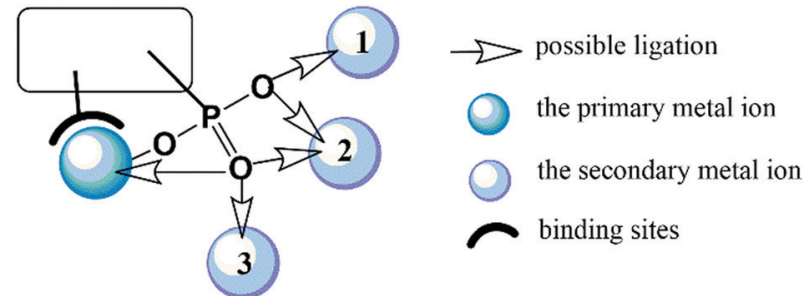

Scheme 1 The coordination modes of a phosphonate-based metalloligand.

one oxygen donor for further coordination (Scheme 1). As far as we are aware, there are only a few types of such metalloligands reported so far, including paddlewheel diruthenium diphosphonate, metallo-polyazamacrocycle-phosphonate, metalloporphyrinphosphonate and metallo-tris-bipyridine-phosphonate ligands. These metalloligands share a common feature in that they can be isolated as discrete species and used as linkers to connect second metal ions. But not all MMPs containing these metalloligands were synthesized using metalloligands as the precursor. In some cases, they were obtained through direct reaction of metal salt and phosphonic acid. In order to give readers a whole picture of these systems, all MMPs containing these metalloligands will be summarized, and their structures and properties will be described. Finally, this article will end up with a discussion of future challenges in this field.

\section{Synthetic strategies}

There are two general synthetic strategies to produce MMPs based on the different precursors as linkers. First, a one-step procedure using phosphonic acid as the precursor. The MMPs can be obtained by direct reaction of appropriate metal salts with phosphonic acids in solution under ambient or hydro/ solvothermal conditions. This approach is simple but challenging in controlling the final products. In particular, when there are more than one kind of metal ions present, it can be difficult to obtain heterometallic MMPs in pure form. Further, the metalloligand could not be formed as anticipated under these one-pot reaction conditions. Second, a two-step procedure using metalloligands as the precursor. This approach involves the preparation of the desired metalloligands, followed by the reaction of the metalloligands with suitable metal salts. The advantage of this approach is that the pre-formed metalloligand can not only immobilize the central metal ion but also provide coordination donors with different orientations, thus allowing the formation of MMPs in a more controllable manner. However, considering the strong coordination capabilities of the phosphonate groups, it could be a challenging task to isolate these phosphonate-based metalloligands as linkers for further assembling with other metal ions. It should be emphasized that in both strategies, other reaction parameters such as the molar ratio and concentration of the metal ion and linkers, the $\mathrm{pH}$ of the reaction mixture, the reaction temperature and time as well as the solvents are also critical 
for achieving crystalline materials of MMPs suitable for singlecrystal X-ray diffraction studies.

\section{Crystal structures}

\subsection{Diruthenium paddlewheel units as metalloligands}

Diruthenium $\mathrm{Ru}_{2}(4+$ to $6+)$ cores with paddlewheel structures are attractive metalloligands for functional MOFs owing to their variable electronic configurations and magnetic and catalytic properties. ${ }^{16}$ Successful examples include those with the paddlewheel dimers constructed from chelating and bridging $\mathrm{O}, \mathrm{O}^{\prime}$-donor ligands, such as carboxylate, ${ }^{17}$ carbonate ${ }^{18}$ and phosphate. ${ }^{19}$ The $\mathrm{Ru}_{2}$-diphosphonate system has superiority over carbonate because the organic groups of the phosphonate ligand can be modified with additional functions. In 2003, we reported the first example of metal phosphonates with extended structures which contain a diruthenium diphosphonate paddlewheel core, $\left(\mathrm{NH}_{4}\right)_{3} \mathrm{Ru}_{2}(\text { hedp })_{2} \cdot 2 \mathrm{H}_{2} \mathrm{O}(\mathbf{1}),{ }^{20}$ where hedpH $_{4}$ is 1-hydroxyethylidenediphosphonic acid $\left[\mathrm{CH}_{3} \mathrm{C}(\mathrm{OH})\right.$ $\left.\left(\mathrm{PO}_{3} \mathrm{H}_{2}\right)_{2}\right]$. This compound was synthesized by a one-pot reaction of $\mathrm{RuCl}_{3}$ and hedpH $\mathrm{H}_{4}$ under hydrothermal conditions. It has a $2 \mathrm{D}$ layer structure in which the negatively charged $\mathrm{Ru}_{2}^{\mathrm{II}, \mathrm{III}}\left(\right.$ hedp) ${ }_{2}{ }^{3-}$ paddlewheels are inter-connected by filling the axial sites of ruthenium with the phosphonate oxygen atoms from the equivalent $\mathrm{Ru}_{2}(\text { hedp })_{2}{ }^{3-}$ units. The interlayer space is filled with $\mathrm{NH}_{4}{ }^{+}$cations and lattice water molecules. Here, the diruthenium motif is not only an acceptor but also a donor (Scheme 2a). A similar layer topology is also found in $\mathrm{Na}_{3} \mathrm{Ru}_{2}$ (hedp) $)_{2} \cdot 4 \mathrm{H}_{2} \mathrm{O}(2) .{ }^{21}$ In this case, the layers are further connected by $\left\{\mathrm{NaO}_{6}\right\}$ octahedra, forming a 3D framework structure.

Interestingly, compound $\mathbf{1}$ is soluble in an aqueous solution of salt with the dissociation of the framework structure and the formation of stable dinuclear species of $\mathrm{Ru}_{2}$ (hedp) ${ }_{2}{ }^{3-}$, confirmed by the isolation of $\mathrm{K}_{3}\left[\mathrm{Ru}_{2}(\text { hedp })_{2}\left(\mathrm{H}_{2} \mathrm{O}\right)_{2}\right] \cdot 6 \mathrm{H}_{2} \mathrm{O} .^{22}$ The pre-formed $\mathrm{Ru}_{2}$ (hedp) ${ }_{2}{ }^{3-}$ paddlewheel is stable in aqueous solution and can provide four pendant phosphonate oxygen atoms and two hydroxyl groups as potential donors. Thus it can serve as a metalloligand to assemble with second metal ions to construct MMPs. Indeed, the direct reaction of $\mathrm{Ru}_{2}(\text { hedp })_{2}{ }^{3-}$ solution with $\mathrm{Ln}\left(\mathrm{NO}_{3}\right)_{3}(\mathrm{Ln}=\mathrm{La}, \mathrm{Ce}, \mathrm{Pr}, \mathrm{Nd}, \mathrm{Sm}, \mathrm{Eu}, \mathrm{Gd}, \mathrm{Tb}, \mathrm{Dy}$, $\mathrm{Ho}, \mathrm{Er})$ at room temperature led to two types of $\mathrm{Ln}-\mathrm{Ru}_{2}$ compounds with the formula $\mathrm{Ln}\left(\mathrm{H}_{2} \mathrm{O}\right)_{4}\left[\mathrm{Ru}_{2}(\text { hedp })_{2}\left(\mathrm{H}_{2} \mathrm{O}\right)_{2}\right] \cdot 5.5 \mathrm{H}_{2} \mathrm{O}$ $\left[\mathrm{Ln}=\mathrm{La}(3)\right.$, Ce (4)] and $\mathrm{Ln}\left(\mathrm{H}_{2} \mathrm{O}\right)_{4}\left[\mathrm{Ru}_{2}(\text { hedp })_{2}\left(\mathrm{H}_{2} \mathrm{O}\right)_{2}\right] \cdot 8 \mathrm{H}_{2} \mathrm{O}$

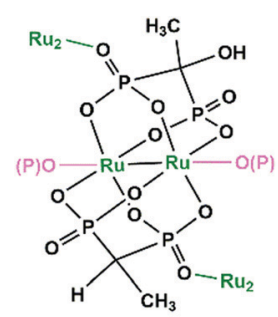

(a)

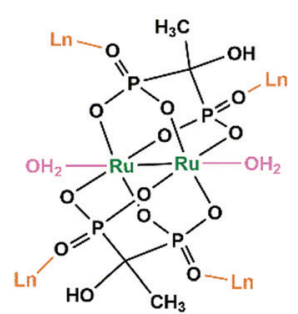

(b)
Scheme 2 Coordination modes of $\mathrm{Ru}_{2}(\mathrm{hedp})_{2}{ }^{n-}$ in 1 (a) and 3-15 (b).

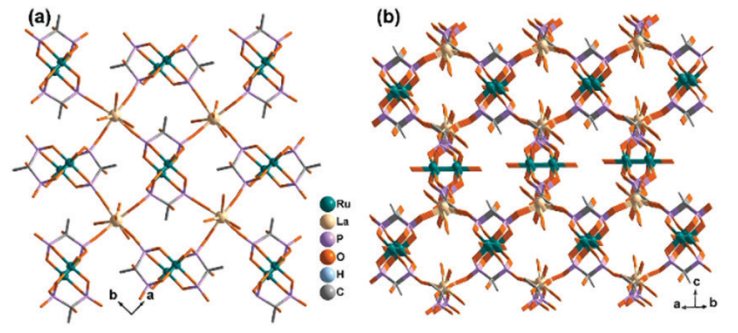

Fig. 1 (a) One square-grid layer of structure 3. (b) 3D PtS-type openframework structure of $\mathbf{5}$. All $\mathrm{H}$ atoms are omitted for clarity. Adapted from ref. 23.

$[\operatorname{Ln}=\operatorname{La}(5), \operatorname{Ce}(\mathbf{6}), \operatorname{Pr}(7), \operatorname{Nd}(\mathbf{8}), \operatorname{Sm}$ (9), Eu (10), Gd (11), Tb (12), Dy (13), Ho (14), Er (15)]. ${ }^{23}$ In all cases, $\mathrm{Ru}_{2}$ (hedp $)_{2}\left(\mathrm{H}_{2} \mathrm{O}\right)_{2}{ }^{3-}$ acts as a tetra-dentate metalloligand, coordinating to four $\mathrm{Ln}^{\mathrm{III}}$ ions using its four pendant phosphonate oxygen atoms (Scheme 2b). Compounds 3 and $\mathbf{4}$ are isostructural. They have a square-grid layer structure in which each $\mathrm{Ru}_{2}$ (hedp) $)_{2}\left(\mathrm{H}_{2} \mathrm{O}\right)_{2}{ }^{3-}$ binds to four $\mathrm{Ln}^{\mathrm{III}}$ ions and vice versa (Fig. 1a). Compounds 5-15 are also isostructural, but possess a 3D PtS-type open-framework structure (Fig. 1b). The lanthanide ions are eight-coordinated by four phosphonate oxygen $\left(\mathrm{O}_{\mathrm{P}}\right)$ atoms and four water molecules $\left(\mathrm{O}_{\mathrm{w}}\right)$ and the hydroxyl groups remain pendant. Despite similar connectivity of $\mathrm{Ru}_{2}(\text { hedp })_{2}\left(\mathrm{H}_{2} \mathrm{O}\right)_{2}{ }^{3-}$ and $\mathrm{Ln}^{\mathrm{III}}$ ions, the significant structural difference between 3-4 and 5-15 originates from the slight difference in the geometry of $\left\{\mathrm{LnOp}_{4} \mathrm{Ow}_{4}\right\}$ polyhedra. In particular, the geometry of $\left\{\mathrm{LnOp}_{4}\right\}$ is essential in determining the topology of the final products, which is a distorted square plane in $\mathbf{3 - 4}$, but closer to a distorted tetrahedron in 5-15. Fig. 1 shows the single layer and the framework structures of $\mathbf{3}$ and 5, respectively. 5 contains three kinds of channels, A (4.3 $\times 3.5 \AA$ along the [330]), B $(3.6 \times 4.9 \AA$ along the [330]) and C $(3.5 \times 3.5 \AA$ along the [001] $)$ (van der Waals radii accounted), which host the lattice water molecules. As far as we are aware, these are the first examples of $\mathrm{Ln}-\mathrm{Ru}_{2}$ heterometallic compounds containing paddlewheel $\mathrm{Ru}_{2}{ }^{n+}$ cores.

By functionalizing the methylenediphosphonate ligand with an amino group, we obtained a $1 \mathrm{D} \mathrm{Ru}_{2}$ (II,II) compound $\left(\mathrm{H}_{3} \mathrm{O}\right)_{2}\left[\mathrm{Ru}_{2}(\mathrm{Hamdp})_{2}\right](\mathbf{1 6})$, where amdp ${ }^{4-}$ represents 1-ammoniummethylene-diphosphonate $\left[\mathrm{NH}_{2} \mathrm{CH}\left(\mathrm{PO}_{3}\right)_{2}{ }^{4-}\right] .16$ is soluble in aqueous solution with the formation of discrete species of $\mathrm{Ru}_{2}$ (Hamdp) $)_{2}$. The assembly of $\mathrm{Ru}_{2}$ (Hamdp) $)_{2}$ with $\mathrm{Ln}\left(\mathrm{NO}_{3}\right)_{3}$ $(\mathrm{Ln}=\mathrm{Dy}, \mathrm{Yb})$ in aqueous solution at room temperature resulted in mixed-valent compound $\mathrm{Dy}\left(\mathrm{H}_{2} \mathrm{O}\right)_{3}\left[\mathrm{Ru}_{2}(\text { Hamdp })_{2}\right]\left[\mathrm{Ru}_{2}(\mathrm{Hamdp})_{2}\right.$ $\left.\left(\mathrm{H}_{2} \mathrm{O}\right)_{2}\right]\left[\mathrm{Ru}_{2} \text { (Hamdp)(amdp) }\right]_{0.5} \cdot 12 \mathrm{H}_{2} \mathrm{O}(17)$ with a $2 \mathrm{D}$ double layer structure and $\mathrm{Yb}\left[\mathrm{Ru}_{2}(\mathrm{Hamdp})_{2}\right]_{2}\left[\mathrm{Ru}_{2}(\operatorname{Hamdp})_{2}\left(\mathrm{H}_{2} \mathrm{O}\right)_{2}\right] \cdot 15 \mathrm{H}_{2} \mathrm{O}$ (18) with a $3 \mathrm{D}$ porous framework structure (Fig. 2). ${ }^{24}$ The mixedvalent nature of the $\mathrm{Ru}_{2}$ units is suggested by their $\mathrm{Ru}-\mathrm{Ru}$ distances and confirmed by magnetic studies.

The structures of $\mathbf{1 7}$ and $\mathbf{1 8}$ are unique compared to other known diruthenium coordination polymers, and hence deserve further description. In $\mathbf{1 7}$, three types of $\mathrm{Ru}_{2}\left(\mathrm{H}_{x} \text { amdp }\right)_{2}$ units are present serving as bi-, tri- and tetra-dentate metalloligands, respectively (Scheme 3a). The coordination of $\mathrm{Ru}_{2}$ (Hamdp) 


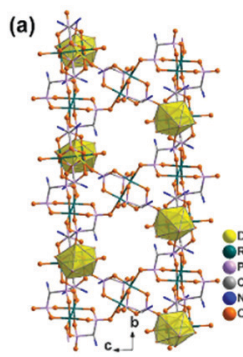

(d)

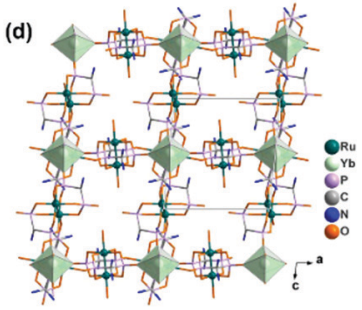

(b)

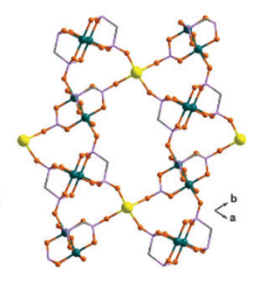

(e)

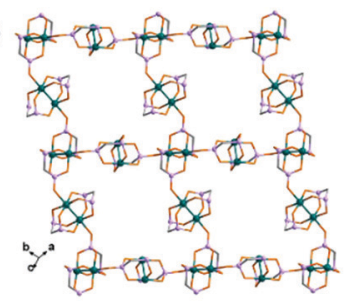

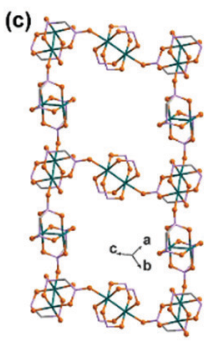

Fig. 2 (a) A double layer structure of 17. (b) The kagomé layer made up of $\mathrm{Ru}_{2}(\mathrm{Hamdp})_{2}^{-}$and Dy ${ }^{\mathrm{III}}$ ions in structure 17. (c) The ladder-like chain of pure $\mathrm{Ru}_{2}$ in structure 17. (d) 3D open-framework structure of 18. (e) The $\mathrm{Ru}_{2}$ layer in structure 18. All $\mathrm{H}$ atoms, $-\mathrm{NH}_{3}{ }^{+}$groups, uncoordinated phosphonate $\mathrm{O}$ atoms and coordination water molecules are omitted in (b, c and e) for clarity. Adapted from ref. 24.

(tri- and tetra-dentate) with Dy ${ }^{\mathrm{III}}$ ions leads to a kagomé layer (Fig. 2b), and two such layers are further pillared by the third type of $\mathrm{Ru}_{2}$ (Hamdp)(amdp) ${ }^{2-}$ (bi-dentate) forming a double layer structure (Fig. 2a and c). In 18, there exist three types of $\mathrm{Ru}_{2}\left(\mathrm{H}_{x} \text { amdp }\right)_{2}$ units acting as bi- and tetra-dentate metalloligands (Scheme $3 \mathrm{~b}$ ). Although the coordination mode of the bi-dentate $\mathrm{Ru}_{2}\left(\mathrm{Ru}_{2}-\mathrm{F}\right.$, Scheme $\left.3 \mathrm{~b}\right)$ is similar to that in $\mathbf{1 7}\left(\mathrm{Ru}_{2}-\mathrm{C}\right.$, Scheme $3 \mathrm{a}$ ), that of the tetra-dentate ones is remarkably different. There are two kinds of tetra-dentate $\mathrm{Ru}_{2}(\text { Hamdp })_{2}{ }^{-}$metalloligands in 18. One of them binds to two other $\mathrm{Ru}_{2}$ units and two $\mathrm{Yb}^{\mathrm{III}}$ ions and accepts two phosphonate oxygen atoms in the (a)

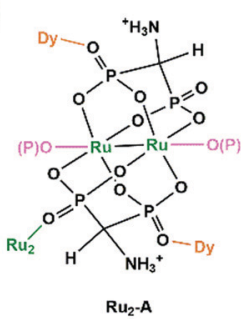

(b)

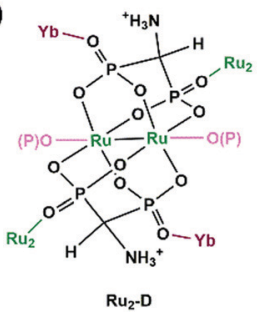

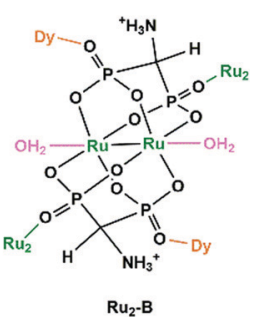

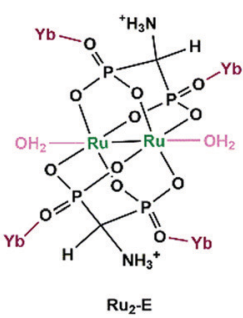

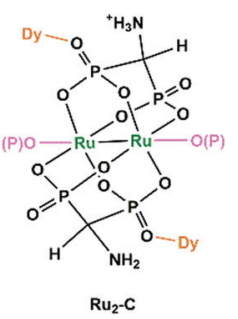

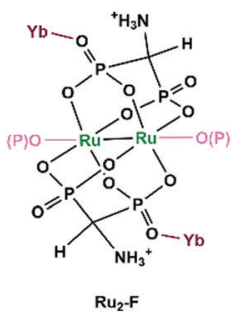

Scheme 3 Coordination modes of $\mathrm{Ru}_{2}\left(\mathrm{H}_{x} \mathrm{amdp}\right)_{2}$ dimers in $\mathbf{1 7}(\mathrm{a})$ and $\mathbf{1 8}$ (b). Reprinted with permission from ref. 24. Copyright 2019, American Chemical Society. axial positions $\left(\mathrm{Ru}_{2}-\mathrm{D}\right)$, while the other binds to four $\mathrm{Yb}^{\mathrm{III}}$ ions with the axial positions filled with water molecules $\left(\mathrm{Ru}_{2}-\mathrm{E}\right)$. These three types of $\mathrm{Ru}_{2}$ units are cross-linked to form a layer containing rhombic eight-member rings of $\mathrm{Ru}_{2}$ (Fig. 2e), unlike four-member rings in $\mathbf{1}$. The $\mathrm{Ru}_{2}$ layers are stacked by sixcoordinated $\mathrm{Yb}$ into a 3D framework (Fig. 2d). The framework contains two kinds of narrow channels, A (approximately $4.1 \times 6.7 \AA$ along the $c$-axis) and B (approximately $6.6 \times 10.6 \AA$ along the $a$-axis) (van der Waals radii not accounted), which host the lattice water molecules.

Apparently, paddlewheel diruthenium diphosphonates can be used as metalloligands to successfully assemble $\mathrm{Ln}-\mathrm{Ru}_{2}$ MMPs. Compared with the $\mathrm{Ru}_{2}$ (hedp) $)_{2} / \mathrm{Ln}$ complexes, ${ }^{23}$ however, compounds 17 and 18 exhibit entirely new structural topologies, attributed to the different charges of the $\mathrm{Ru}_{2}\left(\mathrm{H}_{x} \mathrm{amdp}\right)_{2}$ unit due to the presence of protonated amino group in the diphosphonate ligand. This opens a new route to design and synthesize $\mathrm{Ru}_{2}$-based materials with new architectures by modifying the organic groups of the diphosphonate ligand. Table 1 summarizes MMPs containing $\mathrm{Ru}_{2}$ (hedp) $)_{2}$ and $\mathrm{Ru}_{2}\left(\mathrm{H}_{x} \text { amdp }\right)_{2}$ metalloligands.

\subsection{Metallo-polyazamacrocycle units as metalloligands}

Polyazamacrocycles functionalized by phosphonate groups offer multiple metal binding sites of two distinct types of chemical nature, one at the phosphonate pendant arms and the other within the polyazamacrocycle ring. Table 2 gives the MMPs containing metallo-polyazamacrocycle ligands. 1,4,7Triazacyclononane-1,4,7-triyl-tris(methylenephosphonic acid) $\left(\right.$ notpH $\left.{ }_{6}\right)$ contains the smallest polyazamacrocycle with three nitrogen and nine oxygen atoms as potential coordination donors. It is ideally suited to form six-coordinate complexes with two groups of facial donors: the macrocyclic nitrogen atoms on one side and the pendant phosphonate oxygen atoms on the other side, thus leading to mononuclear species such as $\mathrm{M}^{\mathrm{III}}\left(\right.$ notpH $\left._{3}\right)(\mathrm{M}=\mathrm{Fe}, \mathrm{Co})^{25}$ and $\mathrm{Cu}^{\mathrm{II}}\left(\text { notpH }_{4}\right)^{26}$ (Scheme 4). These mononuclear species are polar and can serve as metalloligands, by using the remaining six uncoordinated phosphonate oxygen atoms, to connect other metal ions into extended networks. Moreover, the octahedrally coordinated $\mathrm{Fe}^{\mathrm{III}}$ or $\mathrm{Co}^{\mathrm{III}}$ centers are chiral showing $\Delta$ or $\Lambda$ configurations. Unfortunately, enantioenriched MMPs containing $\mathrm{M}\left(\operatorname{notpH}_{x}\right)$ metalloligands have not been reported so far. Only in rare cases, racemic conglomerates were obtained which contain an equal amount of opposite enantiomers.

In 2006 we reported the first example of coordination polymers containing the $\mathrm{M}$ (notp) unit with the formula $\mathrm{Mn}_{3}$ (notp) $\left(\mathrm{H}_{2} \mathrm{O}\right)_{6} \cdot 1.5 \mathrm{H}_{2} \mathrm{O}(19),{ }^{27}$ which was obtained by direct reaction of manganese salt and notpH$_{6}$ under hydrothermal conditions. This compound crystallizes in a highly symmetrical trigonal system with space group $R \overline{3}$. Each $\mathrm{Mn}^{\mathrm{II}}$ (notp) ${ }^{4-}$ binds to six $\mathrm{Mn}^{\mathrm{II}}$ ions via corner-sharing of $\left\{\mathrm{PO}_{3} \mathrm{C}\right\}$ tetrahedra and $\left\{\mathrm{MnO}_{6}\right\}$ octahedra (Scheme $5 \mathrm{a}$ ), while each $\left\{\mathrm{MnO}_{6}\right\}$ octahedron is corner-shared with three $\left\{\mathrm{PO}_{3} \mathrm{C}\right\}$ tetrahedra from three equivalent $\mathrm{Mn}^{\mathrm{II}}(\text { notp })^{4-}$ units, thus leading to an inorganic layer containing six-member rings of $\mathrm{Mn}_{3} \mathrm{P}_{3}$ (Fig. 3a). A unique 
Table 1 Metal-metalloligand phosphonates incorporating the $\mathrm{Ru}_{2}$ paddlewheel

\begin{tabular}{|c|c|c|c|c|c|c|c|}
\hline Compound & $\mathrm{Ru}_{2}$ core & Space group & $\begin{array}{l}\mathrm{Ru}-\mathrm{Ru} \\
(\AA)\end{array}$ & $N^{a}$ & Structural feature & $\begin{array}{l}\text { Magnetic property } \\
D\left(\mathrm{~cm}^{-1}\right) / \theta(\mathrm{K}) / z J\left(\mathrm{~cm}^{-1}\right)\end{array}$ & Ref. \\
\hline $\mathrm{Na}_{3} \mathrm{Ru}_{2}(\text { hedp })_{2} \cdot 4 \mathrm{H}_{2} \mathrm{O}(2)$ & $\mathrm{Ru}_{2}{ }^{5+}$ & $C 2 / c$ & 2.354 & $3 \mathrm{D}$ & Open framework & 96.0/0.64/n.a. & 21 \\
\hline$\left\{\mathrm{La}\left(\mathrm{H}_{2} \mathrm{O}\right)_{4}\left[\mathrm{Ru}_{2}(\text { hedp })_{2}\left(\mathrm{H}_{2} \mathrm{O}\right)_{2}\right]\right\} \cdot 5.5 \mathrm{H}_{2} \mathrm{O}(3)$ & $\mathrm{Ru}_{2}{ }^{5+}$ & $P 2_{1} / n$ & 2.357 & $2 \mathrm{D}$ & Square-grid layer & 101.6/n.a./-0.044 & 23 \\
\hline$\left\{\mathrm{Ce}\left(\mathrm{H}_{2} \mathrm{O}\right)_{4}\left[\mathrm{Ru}_{2}(\text { hedp })_{2}\left(\mathrm{H}_{2} \mathrm{O}\right)_{2}\right]\right\} \cdot 5.5 \mathrm{H}_{2} \mathrm{O}(4)$ & $\mathrm{Ru}_{2}{ }^{5+}$ & $P 2_{1} / n$ & 2.357 & $2 \mathrm{D}$ & Square-grid layer & 101.6/n.a./-0.044 & 23 \\
\hline$\left\{\mathrm{La}\left(\mathrm{H}_{2} \mathrm{O}\right)_{4}\left[\mathrm{Ru}_{2}(\text { hedp })_{2}\left(\mathrm{H}_{2} \mathrm{O}\right)_{2}\right]\right\} \cdot 8 \mathrm{H}_{2} \mathrm{O}(5)$ & $\mathrm{Ru}_{2}{ }^{5+}$ & $C 2 / c$ & 2.356 & $3 \mathrm{D}$ & PtS type open-framework & 103.2/n.a./-0.023 & 23 \\
\hline$\left\{\mathrm{Ce}\left(\mathrm{H}_{2} \mathrm{O}\right)_{4}\left[\mathrm{Ru}_{2}(\text { hedp })_{2}\left(\mathrm{H}_{2} \mathrm{O}\right)_{2}\right]\right\} \cdot 8 \mathrm{H}_{2} \mathrm{O}(\mathbf{6})$ & $\mathrm{Ru}_{2}{ }^{5+}$ & $C 2 / c$ & 2.356 & $3 \mathrm{D}$ & PtS type open-framework & n.a. & 23 \\
\hline$\left\{\mathrm{Pr}\left(\mathrm{H}_{2} \mathrm{O}\right)_{4}\left[\mathrm{Ru}_{2}(\text { hedp })_{2}\left(\mathrm{H}_{2} \mathrm{O}\right)_{2}\right]\right\} \cdot 8 \mathrm{H}_{2} \mathrm{O}(7)$ & $\mathrm{Ru}_{2}{ }^{5+}$ & $C 2 / c$ & 2.418 & $3 \mathrm{D}$ & PtS type open-framework & n.a. & 23 \\
\hline$\left\{\mathrm{Nd}\left(\mathrm{H}_{2} \mathrm{O}\right)_{4}\left[\mathrm{Ru}_{2}(\text { hedp })_{2}\left(\mathrm{H}_{2} \mathrm{O}\right)_{2}\right]\right\} \cdot 8 \mathrm{H}_{2} \mathrm{O}(\mathbf{8})$ & $\mathrm{Ru}_{2}{ }^{5+}$ & $C 2 / c$ & 2.351 & $3 \mathrm{D}$ & PtS type open-framework & n.a. & 23 \\
\hline$\left\{\mathrm{Gd}\left(\mathrm{H}_{2} \mathrm{O}\right)_{4}\left[\mathrm{Ru}_{2}(\mathrm{hedp})_{2}\left(\mathrm{H}_{2} \mathrm{O}\right)_{2}\right]\right\} \cdot 8 \mathrm{H}_{2} \mathrm{O}(\mathbf{1 1})$ & $\mathrm{Ru}_{2}{ }^{5+}$ & $C 2 / c$ & 2.354 & 3D & PtS type open-framework & n.a. & 23 \\
\hline$\left\{\mathrm{Tb}\left(\mathrm{H}_{2} \mathrm{O}\right)_{4}\left[\mathrm{Ru}_{2}(\text { hedp })_{2}\left(\mathrm{H}_{2} \mathrm{O}\right)_{2}\right]\right\} \cdot 8 \mathrm{H}_{2} \mathrm{O}(\mathbf{1 2})$ & $\mathrm{Ru}_{2}{ }^{5+}$ & $C 2 / c$ & 2.346 & $3 \mathrm{D}$ & PtS type open-framework & n.a. & 23 \\
\hline$\left\{\mathrm{Dy}\left(\mathrm{H}_{2} \mathrm{O}\right)_{4}\left[\mathrm{Ru}_{2}(\text { hedp })_{2}\left(\mathrm{H}_{2} \mathrm{O}\right)_{2}\right]\right\} \cdot 8 \mathrm{H}_{2} \mathrm{O}(\mathbf{1 3})$ & $\mathrm{Ru}_{2}{ }^{+}$ & $C 2 / c$ & 2.360 & 3D & PtS type open-framework & n.a. & 23 \\
\hline$\left\{\mathrm{Ho}\left(\mathrm{H}_{2} \mathrm{O}\right)_{4}\left[\mathrm{Ru}_{2}(\text { hedp })_{2}\left(\mathrm{H}_{2} \mathrm{O}\right)_{2}\right]\right\} \cdot 8 \mathrm{H}_{2} \mathrm{O}(\mathbf{1 4})$ & $\mathrm{Ru}_{2}{ }^{5+}$ & $C 2 / c$ & 2.353 & $3 \mathrm{D}$ & PtS type open-framework & n.a. & 23 \\
\hline$\left\{\mathrm{Er}\left(\mathrm{H}_{2} \mathrm{O}\right)_{4}\left[\mathrm{Ru}_{2}(\text { hedp })_{2}\left(\mathrm{H}_{2} \mathrm{O}\right)_{2}\right]\right\} \cdot 8 \mathrm{H}_{2} \mathrm{O}(\mathbf{1 5})$ & $\mathrm{Ru}_{2}{ }^{5+}$ & $C 2 / c$ & 2.342 & 3D & PtS type open-framework & n.a. & 23 \\
\hline $\begin{array}{l}\left\{\mathrm{Dy}\left(\mathrm{H}_{2} \mathrm{O}\right)_{3}\left[\mathrm{Ru}_{2}(\mathrm{Hamdp})_{2}\right]\left[\mathrm{Ru}_{2}(\mathrm{Hamdp})_{2}\left(\mathrm{H}_{2} \mathrm{O}\right)_{2}\right]\right. \\
\left.\left[\mathrm{Ru}_{2}(\mathrm{Hamdp})(\mathrm{Hamdp})\right]_{0.5}\right\} \cdot 12 \mathrm{H}_{2} \mathrm{O}(\mathbf{1 7})\end{array}$ & $\mathrm{Ru}_{2}{ }^{5+}$ & $P \overline{1}$ & $\begin{array}{l}2.346- \\
2.358\end{array}$ & $2 \mathrm{D}$ & Pillared-bilayer & n.a./-16.2/n.a. & 24 \\
\hline $\begin{array}{l}\left\{\mathrm{Yb}\left[\mathrm{Ru}_{2}\left(\mathrm{Hamdp}_{2}\right]_{2}\left[\mathrm{Ru}_{2}(\text { Hamdp })_{2}\right.\right.\right. \\
\left.\left.\left(\mathrm{H}_{2} \mathrm{O}\right)_{2}\right]\right\} \cdot 15 \mathrm{H}_{2} \mathrm{O}(\mathbf{1 8})\end{array}$ & $\mathrm{Ru}_{2}{ }^{5+}$ & $P \overline{1}$ & $\begin{array}{l}2.354- \\
2.362\end{array}$ & $3 \mathrm{D}$ & Open framework & n.a./-30.0/n.a. & 24 \\
\hline
\end{tabular}

feature of the layer structure lies in the alignment of the hydrophobic triazacyclononane moieties on one side and the hydrophilic coordinated water molecules on the other side, which results in a polar layer. Two such polar layers are connected by hydrogen bond interactions between the coordination water molecules, leading to a supramolecular double layer structure which is centrosymmetric (Fig. 3b). Notably, direct reactions of uranyl or lanthanide ions with notpH $\mathrm{H}_{6}$ at low $\mathrm{pH}(c a .1)$ resulted in $\mathrm{UO}_{2}\left(\right.$ nopt $\left.\mathrm{H}_{3}\right) \cdot \mathrm{H}_{2} \mathrm{O}^{27}$ and a series of $\mathrm{Ln}$ notp compounds ${ }^{28}$ in which the macrocycle rings are partially protonated without the presence of $\mathrm{M}$ (notp) unit.
Although the overall structure of compound 19 is non-polar, the single layer polarity is retained and extended to the whole structure in compounds $\mathrm{Zn}_{2} \mathrm{Fe}(\operatorname{notp}) \mathrm{Cl}\left(\mathrm{H}_{2} \mathrm{O}\right)(20)$ and $\left[\mathrm{ZnCo}(\right.$ notpH $\left.)\left(\mathrm{H}_{2} \mathrm{O}\right)\right] \cdot 2 \mathrm{H}_{2} \mathrm{O} \quad(21),{ }^{29}$ where $\mathrm{Fe}^{\mathrm{III}}(\text { notp })^{3-}$ and $\mathrm{Co}^{\mathrm{III}}(\text { notpH })^{2-}$ are metalloligands. The two compounds were synthesized by a bottom-up approach using pre-formed $\mathrm{Fe}^{\mathrm{III}}$ $\left(\right.$ notpH $\left._{3}\right)$ or $\mathrm{Co}^{\mathrm{III}}\left(\mathrm{notpH}_{3}\right)$ monomers as precursors. 20 crystallizes in the hexagonal $P 6_{3}$ chiral space group which is also polar. Although the single crystal of $\mathbf{2 1}$ is chiral, the bulk sample is a conglomerate and is circular dichroism silent. Within the structure, the six phosphonate oxygen atoms in

Table 2 Metal-metalloligand phosphonates incorporating polyazamacrocycles

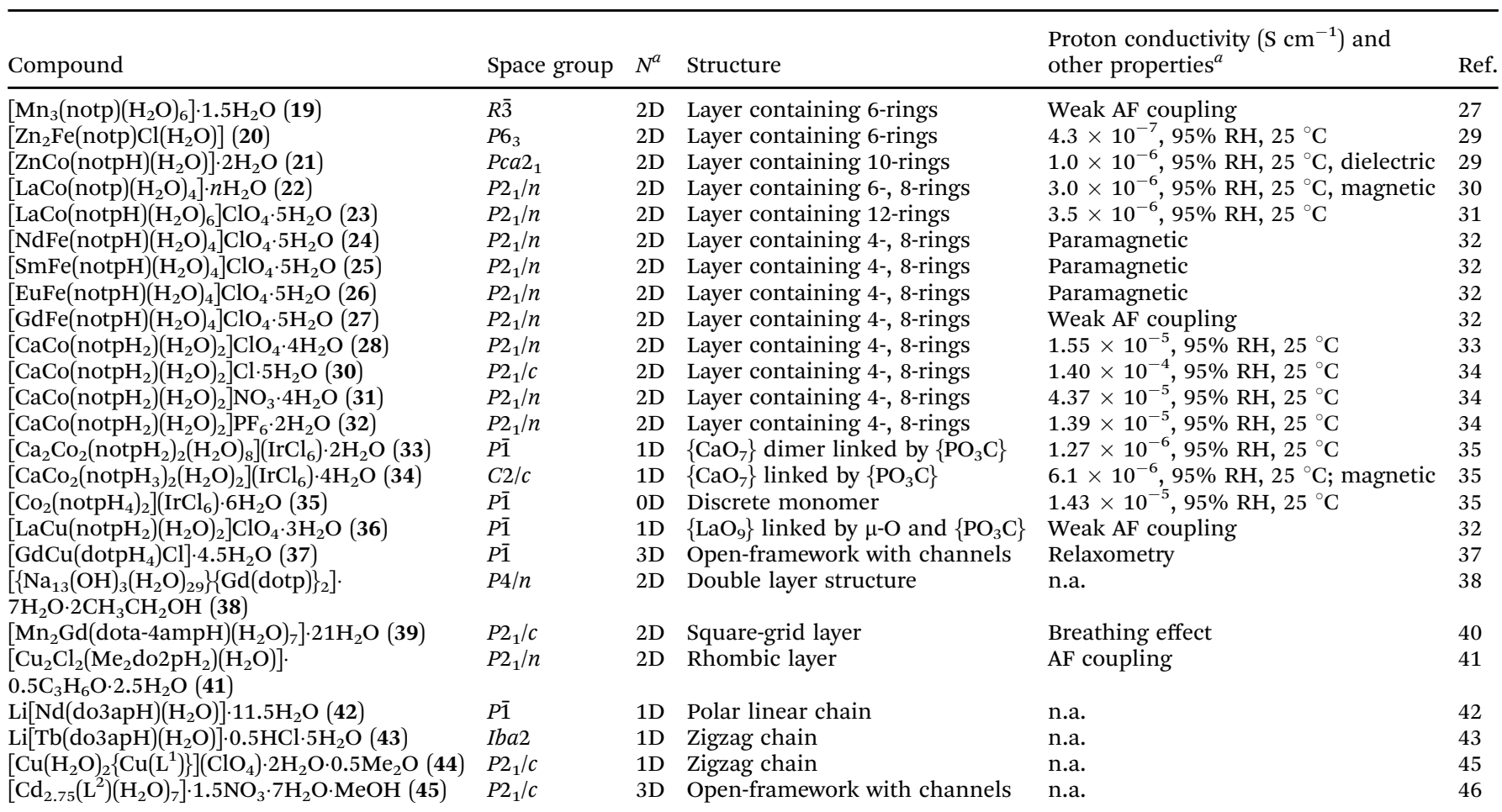

${ }^{a} N$ : dimension of the structure, n.a.: not available, AF: antiferromagnetic. 

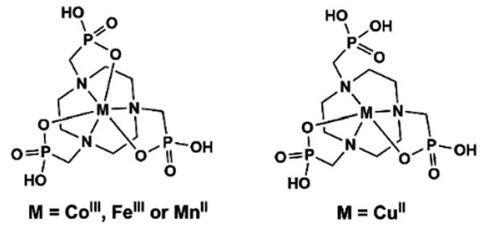

Scheme 4 Molecular structures of metalloligands $M^{\prime \prime \prime}\left(\right.$ notpH $\left._{3}\right)$ and $M^{\prime \prime}\left(\right.$ notpH $\left._{4}\right)$.
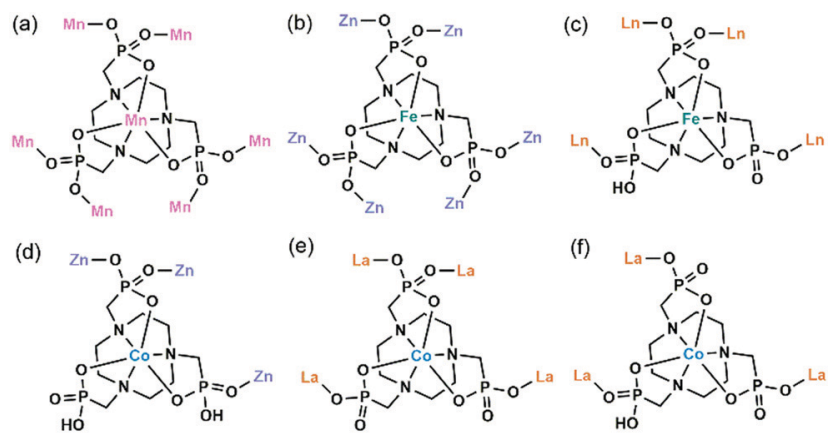

(e)
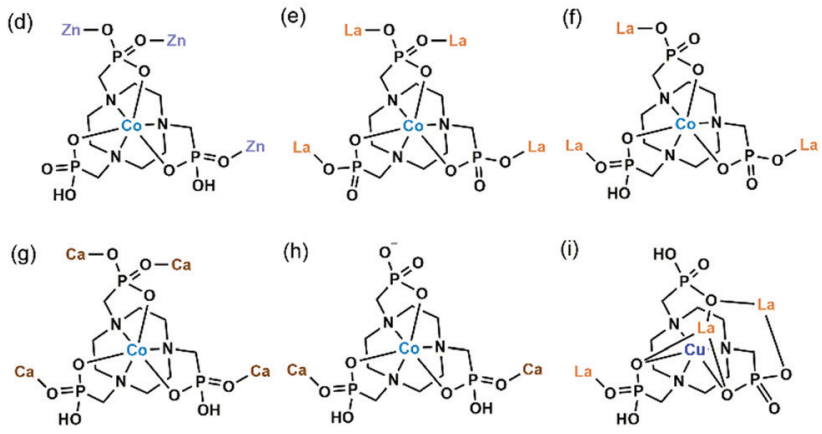

Scheme 5 Coordination modes of $\mathrm{M}\left(\right.$ notpH $\left._{x}\right)$ metalloligands.

$\mathrm{Fe}(\text { notp })_{3}{ }^{-}$are each coordinated to a $\mathrm{Zn}$ atom (Scheme $5 \mathrm{~b}$ ), whereas each $\mathrm{Zn}$ atom is tetrahedrally coordinated by three phosphonate oxygen atoms from three equivalent $\mathrm{Fe}\left(\right.$ notp) ${ }^{3-}$ ligands and one $\mathrm{Cl}^{-}$anion. Such arrangement results in a polar layer containing six-member rings of $\mathrm{Zn}_{2} \mathrm{FeP}_{3}$ with the organic components all residing on the same side of the layer. These polar layers are stacked unidirectionally in an ABAB manner, leading to a polar 3D network structure (Fig. 3c).

The polar structure is also observed in 21. This compound crystallizes in an orthorhombic system, polar space group $\mathrm{PCa}_{1}$. The $\mathrm{Co}(\text { notpH })^{2-}$ metalloligand is tri-dentate (Scheme $\left.5 \mathrm{~d}\right)$. Only three of its six phosphonate oxygen atoms are involved in coordination with three equivalent $\mathrm{Zn}$ atoms, while each $\mathrm{Zn}$ is tetrahedrally coordinated by three phosphonate oxygen atoms from three $\mathrm{Co}(\text { notpH })^{2-}$ ligands and one water molecule. The resulted layer is undulated along the $a$-axis containing ten-member rings of $\mathrm{Zn}_{3} \mathrm{Co}_{2} \mathrm{P}_{5}$. The layer is racemic due to the presence of both $\Delta$ and $\Lambda$ configurations of the cobalt centre. It is polar, however, with the organic components aligning in the same direction along the $c$-axis. The layers are packed unidirectionally to form a polar 3D network (Fig. 3d). The polar nature is confirmed by the dielectric measurements on single crystals of 21 .

In contrast, the bottom-up assembly of $\mathrm{M}^{\mathrm{III}}\left(\operatorname{notpH}_{3}\right)$ $(\mathrm{M}=\mathrm{Co}, \mathrm{Fe})$ metalloligands with lanthanide or calcium ions resulted in products crystallizing in centrosymmetric space groups, possibly due to the fact that both $\mathrm{Ln}^{\mathrm{III}}$ and $\mathrm{Ca}^{\mathrm{II}}$ ions have no significant stereochemical influence on coordination. $\left[\mathrm{LaCo}(\right.$ notp $\left.)\left(\mathrm{H}_{2} \mathrm{O}\right)_{4}\right] \cdot n \mathrm{H}_{2} \mathrm{O}(\mathbf{2 2})^{30}$ and $\left[\mathrm{LaCo}(\right.$ notpH $\left.)\left(\mathrm{H}_{2} \mathrm{O}\right)_{6}\right] \mathrm{ClO}_{4}$.
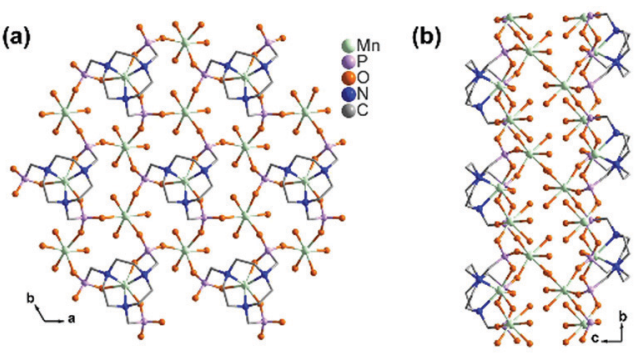

(c)
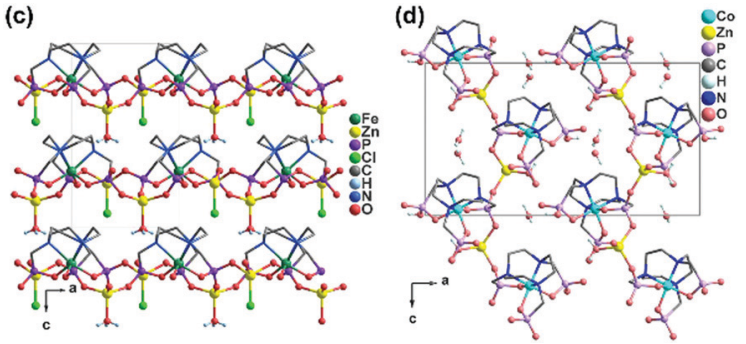

Fig. 3 (a) Single layer and (b) supramolecular double layer of structure 19. (c) Packing diagram of structure 20. (d) Packing diagram of structure 21 . All $\mathrm{H}$ atoms except those attached to oxygen in (d) are omitted for clarity. Adapted from ref. 27 and reproduced from ref. 29 with permission from the Royal Society of Chemistry.

$5 \mathrm{H}_{2} \mathrm{O}(23)^{31}$ can be isolated by reacting $\mathrm{Co}^{\mathrm{III}}\left(\right.$ notpH $\left._{3}\right)$ and $\mathrm{La}\left(\mathrm{ClO}_{4}\right)_{3}$ at different $\mathrm{pH}$, more acidic in the latter case. They crystallize in monoclinic space groups $P 2_{1} / c$ and $P 2_{1} / n$, respectively. In 22, $\mathrm{La}^{\mathrm{III}}$ is eight-coordinated by four phosphonate oxygen atoms and four water molecules. Each $\mathrm{Co}(\text { notp })^{3-}$ acts as a tetradentate metalloligand and links to four La ${ }^{\text {III }}$ ions through four phosphonate oxygen atoms (Scheme 5e), while each $\mathrm{La}$ is connected to four $\mathrm{Co}(\text { notp })^{3-}$ and an equivalent $\mathrm{La}$ atom through phosphonate linkages. This leads to a $2 \mathrm{D}$ waved layer containing 6-member rings of $\mathrm{CoLa}_{2} \mathrm{P}_{3}$ and 8-member rings of $\mathrm{Co}_{2} \mathrm{La}_{2} \mathrm{P}_{4}$ (Fig. $4 \mathrm{a}$ ). The interlayer space is filled with lattice water molecules.
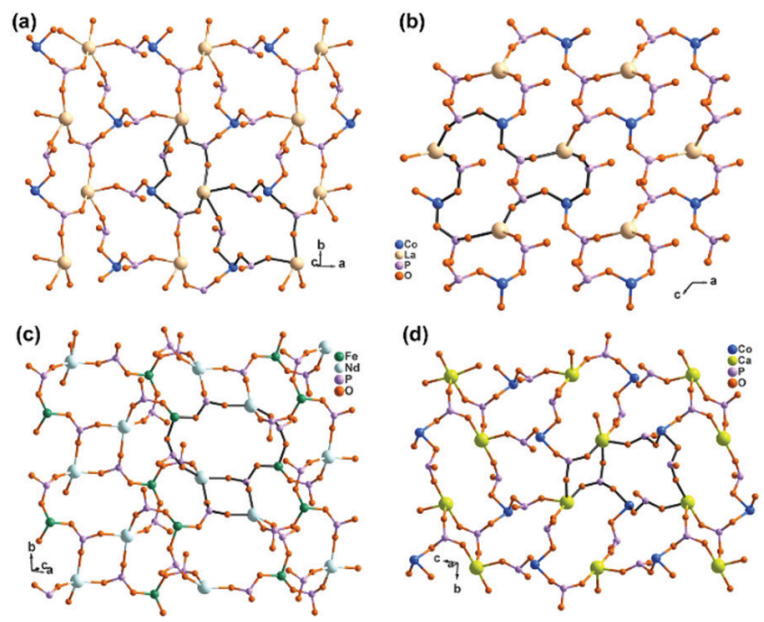

Fig. 4 Layer structures of compounds (a) $\left[\mathrm{LaCo}\left(\right.\right.$ notp) $\left.\left(\mathrm{H}_{2} \mathrm{O}\right)_{4}\right] \cdot n \mathrm{H}_{2} \mathrm{O}$ (22), (b) $\left[\mathrm{LaCo}(\right.$ notpH $\left.)\left(\mathrm{H}_{2} \mathrm{O}\right)_{6}\right] \mathrm{ClO}_{4} \cdot 5 \mathrm{H}_{2} \mathrm{O}$ (23), (c) $\left[\mathrm{NdFe}(\right.$ notpH $\left.)\left(\mathrm{H}_{2} \mathrm{O}\right)_{4}\right] \mathrm{ClO}_{4}$. $5 \mathrm{H}_{2} \mathrm{O}$ (24), and (d) $\left[\mathrm{CaCo}\left(\right.\right.$ notpH $\left.\left.\mathrm{H}_{2}\right)\left(\mathrm{H}_{2} \mathrm{O}\right)_{2}\right]\left(\mathrm{ClO}_{4}\right) \cdot 4 \mathrm{H}_{2} \mathrm{O}$ (28). All C, $\mathrm{N}$ and $\mathrm{H}$ atoms as well as coordination water molecules are omitted for clarity. Adapted from ref. 30-33. 
In $23, \mathrm{La}^{\mathrm{III}}$ is nine-coordinated by three phosphonate oxygen atoms from three $\operatorname{Co}(\operatorname{notpH})^{2-}$, unlike that in 22. Further, one phosphonate group in $\mathrm{Co}(\operatorname{notpH})^{2-}$ is protonated. Each $\mathrm{Co}(\text { notpH })^{2-}$ serves as a tridentate metalloligand connecting to three $\mathrm{La}^{\mathrm{III}}$ ions (Scheme $5 \mathrm{f}$ ). As a result, a layer structure containing 12-member rings of $\mathrm{Co}_{3} \mathrm{La}_{3} \mathrm{P}_{6}$ is constructed, which is completely different from that of 22 (Fig. 4b). The layer is positively charged with the $\mathrm{ClO}_{4}{ }^{-}$counter-anions and lattice water molecules residing in the interlayer space.

Interestingly, similar reactions using $\mathrm{Fe}^{\mathrm{III}}\left(\right.$ notpH $\left._{3}\right)$ instead of $\mathrm{Co}^{\mathrm{III}}\left(\right.$ notpH $\left._{3}\right)$ with lanthanide perchloride resulted in layered compounds $\left[\mathrm{LnFe}(\right.$ notpH $\left.)\left(\mathrm{H}_{2} \mathrm{O}\right)_{4}\right] \mathrm{ClO}_{4} \cdot 5 \mathrm{H}_{2} \mathrm{O}[\mathrm{Ln}=\mathrm{Nd}(24), \mathrm{Sm}$ (25), $\mathrm{Eu}$ (26), Gd (27)] with different structures. ${ }^{32}$ Compounds 24-27 are isostructural, crystallizing in the monoclinic $P 2_{1} / n$ space group. The coordination environment of the $\mathrm{Ln}^{\mathrm{III}}$ ion is similar to that in 22, which is eight-coordinated by four phosphonate oxygen atoms and four water molecules. While the $\mathrm{Fe}(\text { notpH })^{2-}$ metalloligand is analogous to $\mathrm{Co}(\text { notpH })^{2-}$ in 23 with one phosphonate group singly protonated, their coordination modes are different. $\mathrm{Fe}(\text { notpH })^{2-}$ is tetra-dentate (Scheme $5 c)$, whereas $\operatorname{Co}(\text { notpH })^{2-}$ is tri-dentate. Consequently, a different type of layer structure containing 4- and 8-member rings is built up, as seen in Fig. 4c.

The replacement of $\mathrm{La}^{\mathrm{III}}$ by $\mathrm{Ca}^{\mathrm{II}}$ leads to a new layered compound $\left[\mathrm{CaCo}\left(\right.\right.$ notpH $\left.\left._{2}\right)\left(\mathrm{H}_{2} \mathrm{O}\right)_{2}\right]\left(\mathrm{ClO}_{4}\right) \cdot 4 \mathrm{H}_{2} \mathrm{O} \quad(\mathbf{2 8}),{ }^{33}$ where the two phosphonate groups are each singly protonated in order to maintain the overall charge balance. The $\mathrm{Ca}^{\mathrm{II}}$ ion prefers an octahedral coordination geometry with the six sites provided by four phosphonate oxygen atoms and two water molecules. Each $\mathrm{Ca}$ is connected to four $\left[\mathrm{Co}\left(\operatorname{notpH}_{2}\right)\right]^{-}$and vice versa, leading to a $2 \mathrm{D}$ layer with similar topology to that in 24-27 (Fig. 4d and Scheme 5g). Humidity dependent single crystal to single crystal structural transformation is observed for 28, forming a new phase $\left[\mathrm{CaCo}\left(\right.\right.$ notpH $\left.\left._{2}\right)\left(\mathrm{H}_{2} \mathrm{O}\right)_{2}\right]\left(\mathrm{ClO}_{4}\right) \cdot 2 \mathrm{H}_{2} \mathrm{O}$ (29) at low atmosphere humidity, accompanied by a glide of the layer relative to the adjacent layers and a re-arrangement of the hydrogen bond network. The $\mathrm{ClO}_{4}{ }^{-}$in 28 can be replaced by other counter-anions forming $\left[\mathrm{CaCo}\left(\operatorname{notpH} \mathrm{H}_{2}\right)\left(\mathrm{H}_{2} \mathrm{O}\right)_{2}\right] \mathrm{X} \cdot n \mathrm{H}_{2} \mathrm{O}$ $\left[\mathrm{X}=\mathrm{Cl}^{-}(30, n=5), \mathrm{NO}_{3}{ }^{-}(31, n=4), \mathrm{PF}_{6}^{-}(32, n=2)\right]$ with the same layer topology but different number of lattice water molecules. ${ }^{34}$

The counter-anion can be paramagnetic. By incorporating $\mathrm{IrCl}_{6}{ }^{2-}$, trimetallic Co ${ }^{\mathrm{III}}-\mathrm{Ca}^{\mathrm{II}}-\mathrm{Ir}^{\mathrm{IV}}$ compounds $\left[\mathrm{Ca}_{2} \mathrm{Co}_{2}(\text { notpH })_{2}\right.$ $\left.\left(\mathrm{H}_{2} \mathrm{O}\right)_{8}\right]\left(\mathrm{IrCl}_{6}\right) \cdot 2 \mathrm{H}_{2} \mathrm{O}$ (33) and $\left[\mathrm{CaCo}_{2}\left(\operatorname{notpH}_{3}\right)_{2}\left(\mathrm{H}_{2} \mathrm{O}\right)_{2}\right]\left(\mathrm{IrCl}_{6}\right)$. $4 \mathrm{H}_{2} \mathrm{O}(34)$ as well as $\left[\mathrm{Co}_{2}\left(\operatorname{notpH}_{4}\right)_{2}\right]\left(\mathrm{IrCl}_{6}\right) \cdot 6 \mathrm{H}_{2} \mathrm{O}(35)$ were isolated at $\mathrm{pH} 3.5,2.5$ and 1.7 , respectively. ${ }^{35}$ In 33, edge-sharing dimers of $\left\{\mathrm{CaO}_{7}\right\}$ are connected by the bidentate $\left[\mathrm{Co}\left(\text { notpH } \mathrm{H}_{2}\right)\right]^{-}$ metalloligands (Scheme 5h) into infinite chains. 34 also shows a chain structure, made up of $\left\{\mathrm{CaO}_{6}\right\}$ octahedra and $\mathrm{Co}\left(\operatorname{notpH}_{3}\right)$ linkages. In the case of $\mathbf{3 5}$, discrete $\mathrm{Co}\left(\text { notpH }_{4}\right)^{+}$species is found together with the $\mathrm{IrCl}_{6}{ }^{2-}$ anion.

Despite the dominant octahedral geometries of the metal centres in $\mathrm{M}\left(\operatorname{notpH}_{x}\right)\left(\mathrm{M}=\mathrm{Co}^{\mathrm{III}}, \mathrm{Fe}^{\mathrm{III}}, \mathrm{Mn}^{\mathrm{II}}\right)$, the $\mathrm{Cu}^{\mathrm{II}}$ ion favours a square or square pyramidal environment due to the Jahn-Teller distortion. In $\left[\mathrm{LaCu}\left(\operatorname{notpH}_{2}\right)\left(\mathrm{H}_{2} \mathrm{O}\right)_{2}\right] \mathrm{ClO}_{4} \cdot 3 \mathrm{H}_{2} \mathrm{O}(36),{ }^{32}$ the $\mathrm{Cu}^{\mathrm{II}}$ ion in $\mathrm{Cu}\left(\text { notpH }_{2}\right)^{2-}$ has a distorted square pyramidal geometry

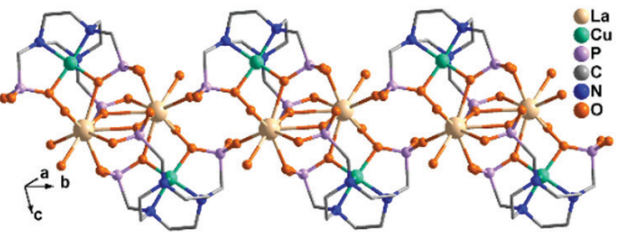

Fig. 5 Chain structure of 36 . All $\mathrm{H}$ atoms are omitted for clarity. Adapted from ref. 32 .

with the basal sites occupied by two $\mathrm{O}$ and two $\mathrm{N}$ donors from the same notpH ${ }_{2}{ }^{4-}$, and axial site by the third nitrogen atom. $\mathrm{Cu}\left(\text { notpH } \mathrm{H}_{2}\right)^{2-}$ serves as a hepta-dentate metalloligand binding to three equivalent La atoms (Scheme 5i). Each La atom is ninecoordinated by seven phosphonate oxygen and two water molecules. Neighbouring La atoms are bridged by $\mathrm{Cu}\left(\operatorname{notpH}_{2}\right)^{2-}$ metalloligands through $\mu_{3}-\mathrm{O}$ and $\mathrm{O}-\mathrm{P}-\mathrm{O}$ units alternatively, forming an infinite chain (Fig. 5).

Other polyazamacrocycle phosphonate ligands that have been commonly studied are 1,4,7,10-tetraazacyclododecane (cyclen) and 1,4,8,11-tetrazacyclotetradecane (cyclam) with one-, two-, three- or four-pendant phosphonate arms. However, most studies were limited to their coordination chemistry in solution due to their utilization in medicine and molecular biology as contrast agents in magnetic resonance imaging (MRI) or metal radioisotope carriers for diagnostic and/or therapeutic purposes. ${ }^{36}$ Coordination polymers incorporating cyclen- or cyclam-phosphonate metalloligands are rare.

An interesting example is $\left[\mathrm{GdCu}\left(\operatorname{dotpH}_{4}\right) \mathrm{Cl}\right] \cdot 4.5 \mathrm{H}_{2} \mathrm{O}(37)^{37}$ reported by Maspoch and co-workers, where $\operatorname{dotpH}_{8}$ represents 1,4,7,10-tetraazacyclododecane-1,4,7,10-tetramethylenephosphonic acid. The compound was synthesized by direct reaction of $\mathrm{CuCl}_{2}$, $\mathrm{Gd}\left(\mathrm{NO}_{3}\right)_{3}$ and $\operatorname{dotpH}_{8}$ in aqueous solution at $85{ }^{\circ} \mathrm{C}$. Within the structure, there are two crystallographically distinguished $\mathrm{Cu}$ atoms ( $\mathrm{Cu} 1, \mathrm{Cu} 2)$, each having a square pyramidal geometry. The basal sites are provided by four $\mathrm{N}$ atoms from the $\operatorname{dotpH}_{4}{ }^{4-}$ ligand and the axial site by the $\mathrm{Cl}^{-}$anion. Each $\mathrm{Cu}\left(\operatorname{dotpH}_{4}\right)^{2-}$ serves as a hexa-dentate metalloligand binding to six Gd atoms (Scheme 6a). There are also two kinds of Gd atoms, Gd1 and $\mathrm{Gd} 2$, each having a distorted octahedral coordination environment. The equivalents of each Gd are doubly bridged by $\mathrm{O}-\mathrm{P}-\mathrm{O}$ units forming $\mathrm{Gd} 1_{2}$ and $\mathrm{Gd} 2_{2}$ dimers. These dimers are further connected by $\mathrm{O}-\mathrm{P}-\mathrm{O}$ units alternatively forming infinite chains. The Gd chains are cross-linked by $\mathrm{Cu}\left(\operatorname{dotpH}_{4}\right)^{2-}$ to construct a 3D open framework structure with one dimensional channels (ca. $5 \times 5 \AA$, van der Waals radii not accounted) (Fig. 6a and b). Notably, the same structure cannot be obtained by replacing $\mathrm{Cu}(\mathrm{II})$ by $\mathrm{Zn}$ (II), Ni(II), Co(II), Mn(II), Fe(III) and Mg(II), likely because they have less preference for nitrogen donors compared to $\mathrm{Cu}(\mathrm{II})$.

Based on the same dotp ligand, Avecilla and co-workers reported a Na-Gd compound, [ $\left.\left\{\mathrm{Na}_{13}(\mathrm{OH})_{3}\left(\mathrm{H}_{2} \mathrm{O}\right)_{29}\right\}\{\mathrm{Gd}(\text { dotp })\}_{2}\right]$. $7 \mathrm{H}_{2} \mathrm{O} \cdot 2 \mathrm{CH}_{3} \mathrm{CH}_{2} \mathrm{OH}(38) .{ }^{38}$ As shown in Fig. 6c, the $\mathrm{Gd}($ dotp) metalloligands in $\mathbf{3 8}$ are dispersed in the $\left\{\mathrm{NaO}_{x}\right\}$ polyhedral network by coordinating to four $\mathrm{Na}$ atoms through their eight pendant phosphonate oxygen atoms forming a layer (Scheme 6b). Two such layers are connected by $\left\{\mathrm{NaO}_{x}\right\}$ polyhedra to form a 

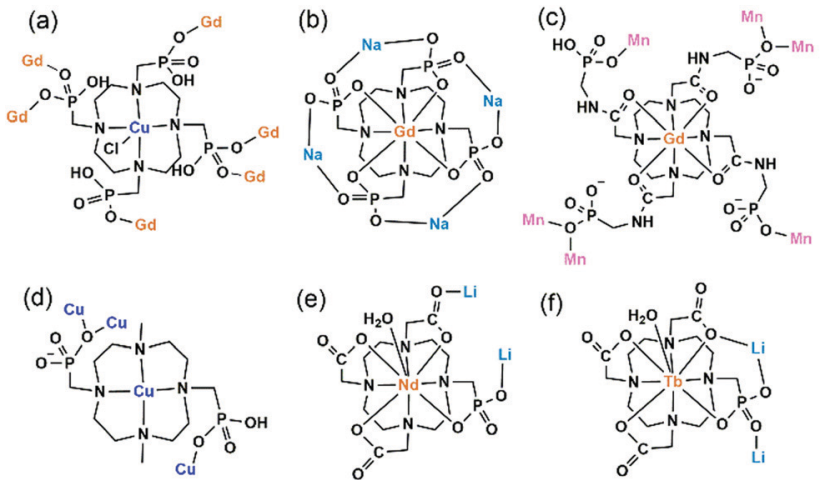

(g)

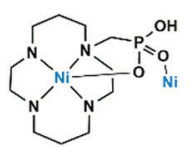

(h)
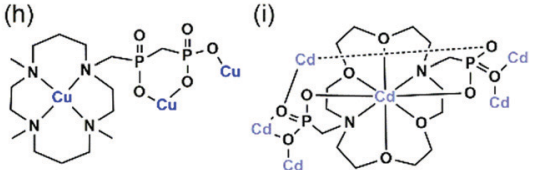

Scheme 6 Coordination modes of metalloligands based on cyclencyclam- and 1,10-diaza-18-crown-6-phosphonate.

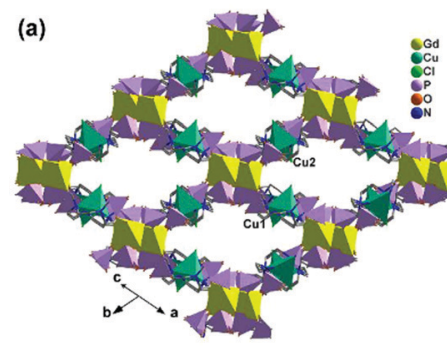

(c)
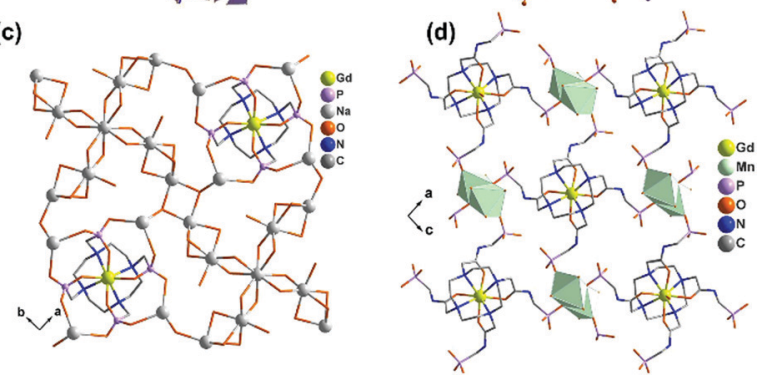

Fig. 6 (a) The 3D open framework structure and (b) the Gd chain connection of 37. (c) Single layer in structure 38. (d) Layer structure made up of $\mathrm{Mn}_{2}\left(\mathrm{PO}_{3}\right)_{4}\left(\mathrm{H}_{2} \mathrm{O}\right)_{6}$ dimers and $\mathrm{Gd}(\mathrm{DOTA}-4 \mathrm{ampH})$ linkages in 39. Adapted from ref. 37,38 and 40 .

double layer structure. If notpH $\mathrm{H}_{8}$ reacted with lanthanide or transition metal salts at low $\mathrm{pH}$, discrete or polymeric compounds can be isolated in which the macrocycle nitrogen atoms are partially protonated and not involved in coordination with metal ions. ${ }^{39}$

1,4,7,10-Tetraazacyclododecane-1,4,7,10-tetraacetamido methylenephosphonic acid (DOTA- $4 \mathrm{ampH}_{8}$ ) has four phosphonic acid arms with an additional acetamido moiety. It is ideally suited to wrap up the lanthanide ion using four $\mathrm{N}$ and four acetoamido $\mathrm{O}$ atoms to form a metalloligand, leaving the four phosphonate groups for further coordination. Maspoch et al. successfully isolated a two-dimensional $\mathrm{Mn}-\mathrm{Gd}$ compound $\left[\mathrm{Mn}_{2} \mathrm{Gd}(\mathrm{DOTA}-4 \mathrm{ampH})\left(\mathrm{H}_{2} \mathrm{O}\right)_{7}\right] \cdot 21 \mathrm{H}_{2} \mathrm{O}$ (39) ${ }^{40}$ using the preformed $\operatorname{Gd}\left(\mathrm{DOTA}-4 \mathrm{ampH}_{x}\right)$ metalloligand as the precursor.
It crystallizes in monoclinic space group $P 2_{1} / c$. The Gd(III) ion is nine-coordinated by four $\mathrm{N}$, four acetoamido $\mathrm{O}$ atoms and one water molecule. The metalloligand $\operatorname{Gd}(\mathrm{DOTA}-4 \mathrm{ampH})$ is hexa-dentate, using four phosphonate oxygen atoms, each from one phosphonate group (Scheme 6c). Two of the four phosphonate oxygen atoms act as $\mu_{3}-\mathrm{O}$ bridging two $\mathrm{Mn}$ atoms, thus forming $\mathrm{Mn}_{2}\left(\mathrm{PO}_{3}\right)_{4}\left(\mathrm{H}_{2} \mathrm{O}\right)_{6}$ dimers. The dimers are connected by the metalloligands in four directions, leading to a layer structure in the $a c$ plane (Fig. 6d). The layers are stacked along the $c$ axis generating $1 \mathrm{D}$ channels with dimensions of approximately $14.8 \times 9.5 \AA$ (van der Waals radii not accounted) where the lattice water molecules reside. Compound 39 shows interesting humidity dependent single-crystal to single-crystal structural transformation, forming $\left[\mathrm{Mn}_{2} \mathrm{Gd}(\right.$ DOTA-4ampH $\left.)\left(\mathrm{H}_{2} \mathrm{O}\right)_{7}\right] \cdot 5 \mathrm{H}_{2} \mathrm{O}$ (40) at $\mathrm{RH}<40 \%$. The transformation causes the layers changing from corrugated to flatter, but the coordination network remains almost the same. Water sorption isotherms show a gate-opening effect at a RH of $c a .85 \%$ upon water adsorption, and a gate-closure effect at RH $55-77 \%$ upon water desorption.

Vizza and co-workers synthesized a cyclen derivative with two phosphonic acid arms, e.g. 4,10-dimethyl-1,4,7,10-tetraazacyclododecane-1,7-bis(methanephosphonic acid) $\left(\mathrm{Me}_{2} \mathrm{do}_{2} \mathrm{pH}_{4}\right)$. The reaction of $\mathrm{Me}_{2} \mathrm{do}_{2} \mathrm{pH}_{4}$ with $\mathrm{Cu}(\mathrm{OAc})_{2}$ at room temperature results in the formation of compound $\left\{\left[\mathrm{Cu}_{2} \mathrm{Cl}_{2}\left(\mathrm{Me}_{2} \mathrm{do} 2 \mathrm{pH}_{2}\right)\left(\mathrm{H}_{2} \mathrm{O}\right)\right]\right.$. $\left.0.5 \mathrm{C}_{3} \mathrm{H}_{6} \mathrm{O} \cdot 2.5 \mathrm{H}_{2} \mathrm{O}\right\}(41) .^{41}$ Analogous to that in 37 , the $\mathrm{Cu}(\mathrm{II})$ ion also has a distorted square-pyramidal coordination geometry with the four basal positions occupied by macrocycle $\mathrm{N}$ atoms and the axial position by $\mathrm{Cl}^{-}$anion. However, the $\mathrm{Cu}\left(\mathrm{Me}_{2} \mathrm{do} 2 \mathrm{pH}_{2}\right)$ metalloligand is tri-dentated (Scheme 6d). Its two phosphonate arms each provide one phosphonate oxygen to bind three $\mathrm{Cu}(\mathrm{II})$ ions. One phosphonate oxygen serves as $\mu_{3}-\mathrm{O}$ bridging two equivalent $\mathrm{Cu}$ atoms to form the $\left\{\mathrm{Cu}_{2} \mathrm{O}_{2}\right\}$ dimer. The dimers are connected by $\mathrm{Cu}\left(\mathrm{Me}_{2} \mathrm{do} 2 \mathrm{pH}_{2}\right)$ in four directions forming a 2D layer containing rhombic rings made up of four metalloligands, four $\mathrm{Cu}$ atoms from $\left\{\mathrm{Cu}_{2} \mathrm{O}_{2}\right\}$ dimers, and eight $\left\{\mathrm{PO}_{3} \mathrm{C}\right\}$ groups (Fig. 7a). The layers are stacked forming a 3D supramolecular network, generating 1D channels along the $a$-axis. The channel size is ca. $5.2 \times 5.8 \AA$ (van der Waals radii not accounted).

By employing a mono(methylphosphonate)-cyclen derivative, 1,4,7,10-tetraazacyclododecane-4,7,10-tris(carboxymethyl)1-methylphosphonic acid $\left(\mathrm{H}_{5} \mathrm{do} \mathrm{a} \mathrm{a}\right)$, Lukeš and co-workers isolated two $\mathrm{Li}-\mathrm{Ln}$ compounds with chain structures, e.g. $\mathrm{Li}\left[\mathrm{Nd}(\mathrm{Hdo} 3 \mathrm{ap})\left(\mathrm{H}_{2} \mathrm{O}\right)\right] \cdot 11.5 \mathrm{H}_{2} \mathrm{O} \quad(\mathbf{4 2})^{42}$ and $\mathrm{Li}[\mathrm{Tb}(\mathrm{Hdo} 3 \mathrm{ap})$ $\left.\left(\mathrm{H}_{2} \mathrm{O}\right)\right] \cdot 0.5 \mathrm{HCl} \cdot 5 \mathrm{H}_{2} \mathrm{O}(43) \cdot{ }^{43}$ In both cases, the $\mathrm{Ln}(\mathrm{III})$ ions are nine-coordinated by four macrocycle $\mathrm{N}$ atoms, three carboxylate $\mathrm{O}$ atoms and one phosphonate $\mathrm{O}$ atom as well as one coordination water molecule. However, the metalloligand $\mathrm{Nd}(\mathrm{Hdo3ap})^{-}$ in $\mathbf{4 2}$ is bi-dentate linking to two Li atoms via one carboxylate $\mathrm{O}$ atom and one phosphonate $\mathrm{O}$ atom (Scheme 6e). But the $\mathrm{Tb}$ (Hdo3ap) ${ }^{-}$in $\mathbf{4 3}$ is tri-dentate, chelating and bridging to two equivalent $\mathrm{Li}$ atoms (Scheme 6f). As a consequence, the tetrahedrally coordinated $\mathrm{Li}(\mathrm{I})$ ions in $\mathbf{4 2}$ are connected by $\mathrm{Nd}(\text { Hdo3ap) })^{-}$into a linear chain which is polar (Fig. 7b). On the other hand, the $\operatorname{Li}(\mathrm{I})$ ions in $\mathbf{4 3}$ are connected by $\mathrm{Tb}$ (Hdo3ap) ${ }^{-}$into a zigzag chain via two phosphonate oxygen 
(a)

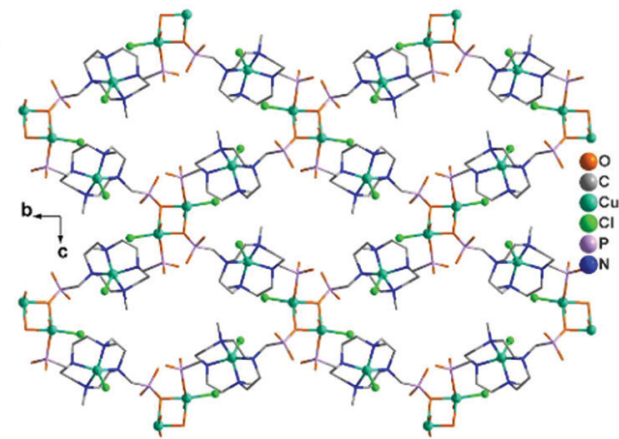

(b)

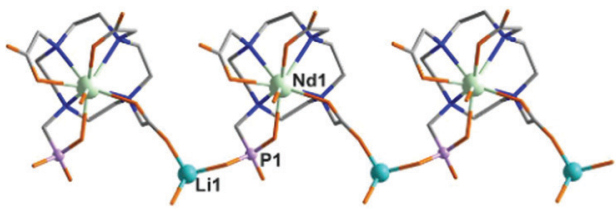

(c)

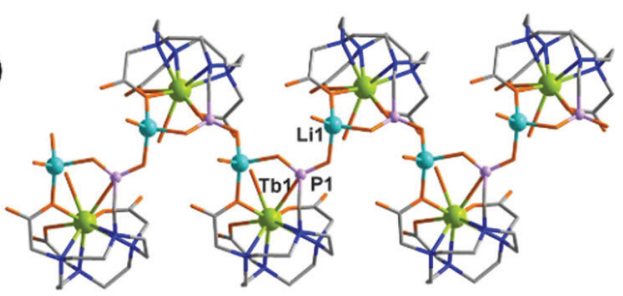

Fig. 7 (a) Single layer of structure $\mathbf{4 1}$. (b) Chain structure of $\mathbf{4 2}$. (c) Chain structure of 55

atoms which is non-polar (Fig. 7c). It should be mentioned that the overall structure of $\mathbf{4 2}$ is non-polar due to the centrosymmetric packing of the polar chains.

As far as we are aware, there are only two coordination polymers containing cyclam-phosphonate metalloligands. One is $\mathrm{Ni}($ cyclam $1 \mathrm{p}),{ }^{44}$ where cyclam-p represents $[(1,4,8,11$-tetraazacyclotetradecan-1-yl)methylene]phosphonic acid. Within the structure, $\mathrm{Ni}($ cyclam1p) serves as both donor and acceptor using one phosphonate oxygen to bind the $\mathrm{Ni}$ atom from the neighbouring unit (Scheme 6g), thus forming an infinite chain. The other is $\left\{\mathrm{Cu}\left(\mathrm{H}_{2} \mathrm{O}\right)_{2}\left[\mathrm{Cu}\left(\mathrm{L}^{1}\right)\right]\right\}\left(\mathrm{ClO}_{4}\right) \cdot 2 \mathrm{H}_{2} \mathrm{O} \cdot 0.5$ acetone (44) ${ }^{45}$ isolated by Kotek and co-workers, where the cyclam derivative $\mathrm{H}_{3} \mathrm{~L}^{1}$ contains a single diphosphonate arm. In this case, $\mathrm{Cu}\left(\mathrm{L}^{1}\right)$ serves as a tri-dentate metalloligand (Scheme $6 \mathrm{~h}$ ), chelating and bridging the $\mathrm{Cu}(\mathrm{II})$ ions into infinite zigzag chains. The chain consists of corner sharing $\left\{\mathrm{CuO}_{5}\right\}$ square pyramids and $\left\{\mathrm{PO}_{3} \mathrm{C}\right\}$ tetrahedra. The cyclam moieties are pendant on the two sides of the inorganic chain (Fig. 8a).

Clearfield and co-workers employed $N, N^{\prime}$-bis(phosphonomethyl)1,10-diaza-18-crown-6 $\left(\mathrm{H}_{4} \mathrm{~L}^{2}\right)$, and isolated compound $\mathrm{Cd}_{2.75}\left(\mathrm{~L}^{2}\right)\left(\mathrm{H}_{2} \mathrm{O}\right)_{7} \cdot 1.5 \mathrm{NO}_{3} \cdot 7 \mathrm{H}_{2} \mathrm{O} \cdot \mathrm{MeOH}(45)$ with an open framework structure. ${ }^{46}$ Within the metalloligand $\mathrm{Cd}\left(\mathrm{L}^{2}\right)^{2-}$, the $\mathrm{Cd}$ atom is eight-coordinated by four $\mathrm{O}$ and two $\mathrm{N}$ atoms from the crown ring and two $\mathrm{O}$ atoms from the phosphonate arms. The metalloligand is hepta-dentate, chelating and bridging five $\mathrm{Cd}$ atoms (Scheme 6i). A pentanuclear $\mathrm{Cd}_{5}$ cluster is found, where the central $\left\{\mathrm{CdO}_{8}\right\}$ is edge-shared with four $\left\{\mathrm{CdO}_{6}\right\}$ octahedra. Each $\mathrm{Cd}_{5}$ cluster is connected to four $\mathrm{Cd}\left(\mathrm{L}^{2}\right)^{2-}$, forming a $\mathrm{Cd}_{5}\left\{\mathrm{Cd}_{4}\left(\mathrm{~L}^{2}\right)_{4}\right\}$ cluster
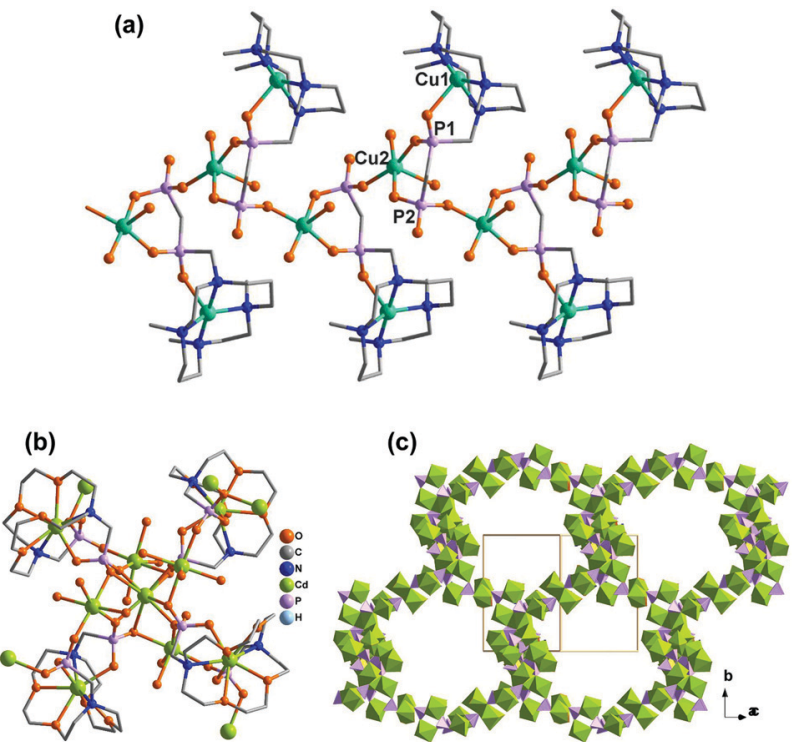

Fig. 8 (a) Chain structure of 44. (b) The $\mathrm{Cd}_{5}\left\{\mathrm{Cd}_{4}\left(\mathrm{~L}^{2}\right)_{4}\right\}$ cluster and (c) packing diagram of structure 45 . The $\mathrm{C}, \mathrm{N}$ and $\mathrm{H}$ atoms in (c) are omitted for clarity. Colour codes: $\left\{\mathrm{CdO}_{8}\right\}$ and $\left\{\mathrm{CdO}_{6}\right\}$ green, $\left\{\mathrm{PO}_{3} \mathrm{C}\right\}$ purple.

(Fig. 8b). The $\mathrm{Cd}_{5}\left\{\mathrm{Cd}_{4}\left(\mathrm{~L}^{2}\right)_{4}\right\}$ clusters are cross-linked via $\left\{\mathrm{Cd}_{2} \mathrm{O}_{2}\right\}$ dimers, forming a 3D framework structure (Fig. 8c). The channel sizes are $c a .4 .2 \times 4.2 \AA$ along the $c$ axis or $9.3 \times 14.1 \AA$ towards (0 5 -4) (van der Waals radii not accounted), respectively.

To summarize, metallo-polyazamacrocycle-phosphonates can be used as efficient metalloligands for the construction of MMPs with structures ranging from 1D chain, 2D layer to 3D framework. For metallo-polyazamacrocyles with four, three, or two phosphonate arms, they usually form 2D layer structures with second metal ions. Only in a few cases, 1D chain or 3D open framework structures are observed. In contrast, metallopolyazamacrocycles with one phosphonate arm tend to form a 1D chain structure. This statement is not rigorous, however, as the given examples are still extremely limited. The formation of a particular structure is highly dependent on the reaction conditions, the coordination geometries of the second metal ions and the involvement of metal clusters as nodes. In addition, these metalloligands possess a unique feature of polarity that distinguishes them from many other phosphonate ligands. This feature together with their structural diversity and tuneable composition endows them with advantages in the design and synthesis of materials with multifunction.

\subsection{Metalloporphyrin units as metalloligands}

Porphyrins and their complexes have attracted intensive research interest across many fields due to their rich coordination chemistry and photophysical, redox and catalytic properties. ${ }^{47}$ In recent years a number of metal-organic frameworks (MOFs) have been obtained using metalloporphyrins as building units. ${ }^{48}$ Especially Zr-MOFs containing $\mathrm{H}_{2} \mathrm{TCPP}^{4-}$ are highly porous and stable. ${ }^{49}$ However, it is still a great challenge to construct MMPs incorporating metalloporphyrins, especially those based on metalloporphyrinphosphonic acids, due to the difficulties in synthesizing 
Table 3 Metal-metalloligand phosphonates incorporating metalloporphyrins, cyclometalate or metal-polypyridine

\begin{tabular}{|c|c|c|c|c|c|}
\hline Compound & Space group & $N^{a}$ & Structure & $\begin{array}{l}\text { Proton conductivity }\left(\mathrm{S} \mathrm{cm}^{-1}\right) \text { and } \\
\text { other properties }^{a}\end{array}$ & Ref. \\
\hline $\mathrm{Cu}_{2}\left({ }^{t} \mathrm{BuCOO}\right)_{4}\{\mathrm{Cu}(\mathrm{DEPPP})\}(46)$ & $P \overline{1}$ & $1 \mathrm{D}$ & Linear chain & n.a. & 54 \\
\hline $\mathrm{Cu}_{2}\left({ }^{t} \mathrm{BuCOO}\right)_{4}\{\mathrm{Pd}(\mathrm{DEPPP})\}(47)$ & $P \overline{1}$ & $1 \mathrm{D}$ & Linear chain & n.a. & 54 \\
\hline $\mathrm{Cu}_{2}\left({ }^{t} \mathrm{BuCOO}\right)_{4}\{\mathrm{Ni}(\mathrm{DEPPP})\}(48)$ & $C 2 / c$ & 1D & Zigzag chain & n.a. & 54 \\
\hline $\mathrm{MnNi}\left(\mathrm{TPPPH}_{6}\right)\left(\mathrm{H}_{2} \mathrm{O}\right)(49)$ & $P \overline{1}$ & $3 \mathrm{D}$ & Framework isostructural to $\mathbf{5 1}$ & $\mathrm{N}_{2}$ and $\mathrm{H}_{2} \mathrm{O}$ sorption & 60 \\
\hline $\mathrm{CoNi}\left(\mathrm{TPPPH}_{6}\right)\left(\mathrm{H}_{2} \mathrm{O}\right)(\mathbf{5 0})$ & $P \overline{1}$ & $3 \mathrm{D}$ & Framework isostructural to $\mathbf{5 1}$ & $\mathrm{N}_{2}$ and $\mathrm{H}_{2} \mathrm{O}$ sorption & 60 \\
\hline $\mathrm{NiNi}\left(\mathrm{TPPPH}_{6}\right)\left(\mathrm{H}_{2} \mathrm{O}\right)(\mathbf{5 1})$ & $P \overline{1}$ & $3 \mathrm{D}$ & Open-framework with channels & $5.6 \times 10^{-6}, 90 \% \mathrm{RH}, 80^{\circ} \mathrm{C}$ & 60 \\
\hline $\mathrm{CdNi}\left(\mathrm{TPPPH}_{6}\right)\left(\mathrm{H}_{2} \mathrm{O}\right)(52)$ & $P \overline{1}$ & $3 \mathrm{D}$ & Framework isostructural to $\mathbf{5 1}$ & $\mathrm{N}_{2}$ and $\mathrm{H}_{2} \mathrm{O}$ sorption & 60 \\
\hline $\mathrm{Zn}_{3}\left[\mathrm{Ni}\left(\mathrm{TPPPH}_{3}\right)_{3}\right] \cdot 9\left(\mathrm{CH}_{3}\right)_{2} \mathrm{NH}_{2} \cdot 3 \mathrm{DMF} \cdot 17 \mathrm{H}_{2} \mathrm{O}(53)$ & $C 2 / c$ & $3 \mathrm{D}$ & Open-framework with channels & $1.55 \times 10^{-3}, 80 \% \mathrm{RH}, 75{ }^{\circ} \mathrm{C}$ & 61 \\
\hline$\left[\mathrm{Co}_{2} \mathrm{Ni}\left(\mathrm{TPPPH}_{4}\right)\right] \cdot 2 \mathrm{DABCO} \cdot 6 \mathrm{H}_{2} \mathrm{O}(54)$ & $P \overline{4} c 2$ & $3 \mathrm{D}$ & Open-framework with channels & $\mathrm{N}_{2}$ sorption, BET: $700 \mathrm{~m}^{2} \mathrm{~g}^{-1}$ & 62 \\
\hline$\left[\mathrm{Zr}_{2} \mathrm{Ni}\left(\mathrm{TPPPH}_{2}\right)(\mathrm{OH} / \mathrm{F})_{2}\right](\mathbf{5 5})$ & $I 4_{1} /$ acd & $3 \mathrm{D}$ & Open-framework with channels & BET: $1070 \mathrm{~m}^{2} \mathrm{~g}^{-1}, \mathrm{CV}, \mathrm{UV}-\mathrm{vis}$ & 63 \\
\hline$\left[\mathrm{Hf}_{2} \mathrm{Ni}\left(\mathrm{TPPPH}_{2}\right)(\mathrm{OH} / \mathrm{F})_{2}\right](\mathbf{5 6})$ & $I 4_{1} /$ acd & 3D & Open-framework with channels & BET: $1030 \mathrm{~m}^{2} \mathrm{~g}^{-1}, \mathrm{UV}$-vis & 63 \\
\hline$\left[\mathrm{Na}_{2} \mathrm{Cu}\left(\mathrm{TPPPH} \mathrm{H}_{4}\right)\right] \cdot\left(\mathrm{NH}_{2}\left(\mathrm{CH}_{3}\right)_{2}\right)_{2}(57)$ & $P \overline{1}$ & $3 \mathrm{D}$ & Open-framework with channels & BET: $697 \mathrm{~m}^{2} \mathrm{~g}^{-1}$ & 64 \\
\hline$\left[\mathrm{EuIr}_{6}(\mathrm{ppy})_{12}(\mathrm{bpp})_{2}(\mathrm{bppH})_{4}\right]\left(\mathrm{CF}_{3} \mathrm{SO}_{3}\right) \cdot x \mathrm{H}_{2} \mathrm{O}(58)$ & $P \overline{1}$ & OD & Supramolecular framework & Phosphorescence & 65 \\
\hline$\left[\mathrm{TbIr}_{6}(\mathrm{ppy})_{12}(\mathrm{bpp})_{2}(\mathrm{bppH})_{4}\right]\left(\mathrm{CF}_{3} \mathrm{SO}_{3}\right) \cdot x \mathrm{H}_{2} \mathrm{O}(59)$ & $P \overline{1}$ & 0D & Supramolecular framework & Phosphorescence & 65 \\
\hline$\left[\mathrm{DyIr}_{6}(\mathrm{ppy})_{12}(\mathrm{bpp})_{2}(\mathrm{bppH})_{4}\right]\left(\mathrm{CF}_{3} \mathrm{SO}_{3}\right) \cdot x \mathrm{H}_{2} \mathrm{O}(\mathbf{6 0})$ & $P \overline{1}$ & $0 \mathrm{D}$ & Supramolecular framework & Phosphorescence, magnetic & 65 \\
\hline$\left[\mathrm{ErIr}_{6}(\mathrm{ppy})_{12}(\mathrm{bpp})_{2}(\mathrm{bppH})_{4}\right]\left(\mathrm{CF}_{3} \mathrm{SO}_{3}\right) \cdot x \mathrm{H}_{2} \mathrm{O}(\mathbf{6 1})$ & $P \overline{1}$ & OD & Isostructural to $58-60$ & Phosphorescence, magnetic & 65 \\
\hline$\left[\mathrm{YbIr}_{6}(\mathrm{ppy})_{12}(\mathrm{bpp})_{2}(\mathrm{bppH})_{4}\right]\left(\mathrm{CF}_{3} \mathrm{SO}_{3}\right) \cdot x \mathrm{H}_{2} \mathrm{O}(62)$ & $P \overline{1}$ & $0 \mathrm{D}$ & Isostructural to $\mathbf{5 8 - 6 0}$ & Phosphorescence, magnetic & 65 \\
\hline$\left[\mathrm{La}_{3}\left(\mathrm{H}_{2} \mathrm{O}\right)_{9}\left\{\mathrm{Ru}\left(4,4^{\prime}-\mathrm{dpbpy}\right)_{3} \mathrm{H}_{5.5}\right\}_{2}\right] \cdot n \mathrm{H}_{2} \mathrm{O}(63)$ & $P 2_{1} / n$ & $3 \mathrm{D}$ & Isostructural to 64 & $2.8 \times 10^{-6}, 95 \% \mathrm{RH}, 25^{\circ} \mathrm{C}$ & 66 \\
\hline $\mathrm{Pr}_{3}\left[\mathrm{Ru}(\mathrm{DPBPY})_{3} \mathrm{H}_{5.5}\right]_{2}(\mathbf{6 4})$ & $P 2_{1} / n$ & $3 \mathrm{D}$ & Open-framework with channels & $3.7 \times 10^{-6}, 95 \% \mathrm{RH}, 25{ }^{\circ} \mathrm{C}$ & 66 \\
\hline$\left[\mathrm{GdCo}^{\mathrm{III}}\left(5,5^{\prime}-\mathrm{dpbpyH}_{2}\right)_{3}\left(\mathrm{H}_{2} \mathrm{O}\right)_{2}\right] \cdot 6.5 \mathrm{H}_{2} \mathrm{O}(65)$ & $C 2 / c$ & $2 \mathrm{D}$ & Isostructural to 67 & Magnetic & 67 \\
\hline$\left[\mathrm{DyCo}^{\mathrm{III}}\left(5,5^{\prime}-\mathrm{dpbpyH}_{2}\right)_{3}\left(\mathrm{H}_{2} \mathrm{O}\right)_{2}\right] \cdot 6.5 \mathrm{H}_{2} \mathrm{O}(66)$ & $C 2 / c$ & $2 \mathrm{D}$ & Isostructural to 67 & Magnetic & 67 \\
\hline$\left.\left[\mathrm{TbCo}^{\mathrm{III}}\left(5,5^{\prime}-\mathrm{dpbpyH}\right)_{3}\right)_{3}\left(\mathrm{H}_{2} \mathrm{O}\right)_{2}\right] \cdot 6.5 \mathrm{H}_{2} \mathrm{O}(67)$ & $C 2 / c$ & $2 \mathrm{D}$ & Layer with $(4,4)$ connectivity & Magnetic & 67 \\
\hline$\left[\mathrm{Gd}\left\{\mathrm{Ni}^{\mathrm{II}}\left(5,5^{\prime}-\mathrm{dpbpy}\right)_{3} \mathrm{H}_{7}\right\}\left(\mathrm{H}_{2} \mathrm{O}\right)_{3}\right] \mathrm{NaCl} \cdot 6 \mathrm{H}_{2} \mathrm{O}(\mathbf{6 8})$ & $C 2$ & 3D & Open-framework with channels & Magnetic & 67 \\
\hline
\end{tabular}

${ }^{a} N$ : dimension of the structure, n.a.: not available. UV-vis absorption spectra and cyclic voltammetry (CV) measurements were carried out in solution.

the metalloligands and in forming crystalline materials with sufficient size for structural determination. Table 3 gives the known MMPs based on the metalloporphyrins shown in Scheme 7.

Gorbunova and co-workers synthesized a mesophosphorylporphyrin, e.g. 5,15-bis(diethoxyphosphoryl)-10,20diphenylporphyrin (DEPPP, Scheme 7a), through Pd-catalyzed coupling reactions. The solution reactions of $\mathrm{H}_{2}$-DEPPP with metal salts resulted in compounds $\mathrm{M}$ (DEPPP) $\left(\mathrm{M}=\mathrm{Zn},{ }^{50} \mathrm{Cu},{ }^{51}\right.$ $\mathrm{Cd}^{52}$ ) with similar layer structures, where DEPPP serves as both donor and acceptor. For M(DEPPP) ( $\mathrm{M}=\mathrm{Pt}, \mathrm{Pd}, \mathrm{Ni})$, layered coordination polymers cannot be obtained because the central

(a)

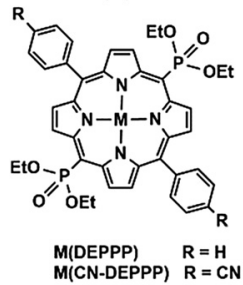

(d)

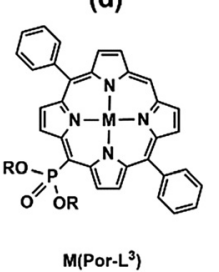

Scheme 7 Molecular ligands. metal ions favour a four-coordinated square-planar geometry. ${ }^{52}$ Another related 2D polymeric MMP is $\mathrm{Zn}(\mathrm{CN}-\mathrm{DEPPP})$ based on 5,15-bis(diethoxyphosphoryl)-10,20-bis(4'-cyanophenyl) porphyrin (CN-DEPPP, Scheme 7a), described by Kadish and co-workers. ${ }^{53}$ The electrochemical properties were studied for all these compounds.

Direct reactions of $\mathrm{Cu}_{2}\left({ }^{t} \mathrm{BuCOO}\right)_{4}\left(\mathrm{CH}_{3} \mathrm{CN}\right)_{2}$ and $\mathrm{M}(\mathrm{DEPPP})$ $(\mathrm{M}=\mathrm{Cu}, \mathrm{Pd}, \mathrm{Ni})$ in chloroform resulted in the formation of compounds $\mathrm{Cu}_{2}\left({ }^{t} \mathrm{BuCOO}\right)_{4}\{\mathrm{M}(\mathrm{DEPPP})\}[\mathrm{M}=\mathrm{Cu}(46), \mathrm{Pd}(47), \mathrm{Ni}$ (48)]. ${ }^{54}$ These compounds display similar zigzag chain structures, where the paddlewheel dimers of $\mathrm{Cu}_{2}\left({ }^{t} \mathrm{BuCOO}\right)_{4}$ are connected by the M(DEPPP) metalloligands (Fig. 9a). In 46, there exist two kinds of $\mathrm{Cu}$ atoms. One locates at the centre of the porphyrin cavities adopting a square-planar $\mathrm{CuN}_{4}$ environment. The other incorporates in the paddlewheel unit showing a square-pyramidal $\mathrm{CuO}_{5}$ geometry with the apical site occupied by phosphoryl $\mathrm{O}$ atom. It is noted that the geometry of the porphyrin macrocycle can be rather different depending on the central metal ion. A strong nonplanarity of the porphyrin core is observed only for Ni(DEPPP). This leads to the formation of a zigzag chain in 48 , instead of a linear chain as in 46 and 47 . The packing of the zigzag chains results in regular pores in the crystal with dimensions of $c a .10 \times 12 \AA$ (van der Waals radii not accounted) (Fig. 9b).

Recently, Ermakova et al. developed synthetic routes to accessing mono(diethoxyphosphorylporphyrins) with different substitutes. Compounds $\mathrm{Zn}\left(\text { Por- } \mathrm{L}^{1}\right)^{55}$ (Scheme $7 \mathrm{~b}$ ) and $\mathrm{Zn}\left(\text { Por-L }{ }^{2}\right)^{56}$ (Scheme 7c) show chain structures, where the porphyrin macrocycle units are connected to each other through coordination of zinc with phosphoryl $\mathrm{O}$ atoms. Apart from these polymers, discrete dimeric or tetrameric compounds were also reported 
(a)

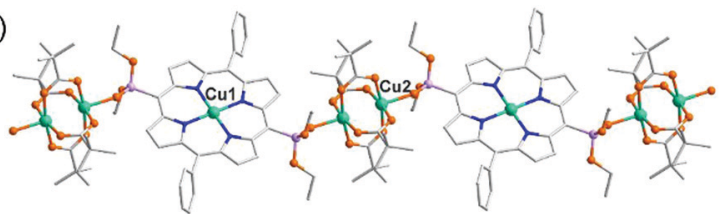

(b)

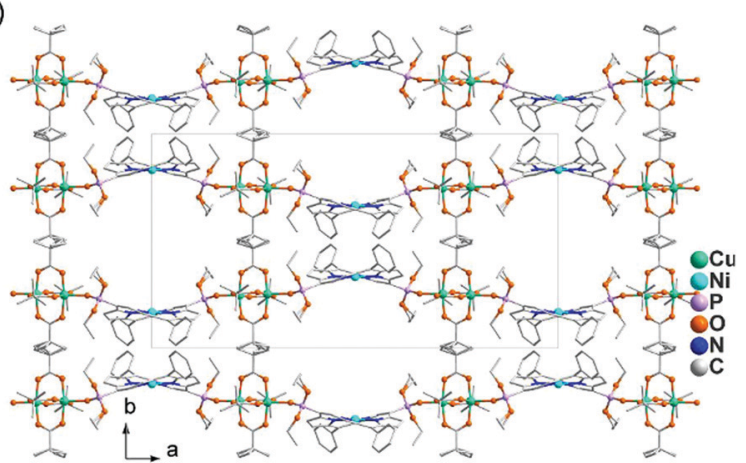

Fig. 9 (a) Linear chain structure of $\mathbf{4 6}$. (b) Zigzag chain structure of $\mathbf{4 8}$ Adapted from ref. 50 and 54

based on zinc complexes of 10-(dialkoxyphosphoryl)-5,15diarylporphyrinates or $\beta$-dialkoxyphosphoryl-5,10,15,20tetraphenylporphyrins (Por- $\mathrm{L}^{3}$, Scheme $7 \mathrm{~d}$ ), ${ }^{57}$ and gallium(III) and indium(III) complexes of meso-mono(diethoxyphosphoryl) porphyrins (Por- $\mathrm{L}^{4}$, Scheme $\left.7 \mathrm{e}\right) .{ }^{58}$

Noting that the diethoxyphosphoryl group can provide only one oxygen donor for coordination and the resulted $\mathrm{M}-\mathrm{O}(\mathrm{P})$ bond is weak, it is highly desired to prepare metal phosphonates using porphyrin-phosphonic acids as ligands. A typical ligand is tetra(4-phosphonophenyl)porphyrin $\left(\mathrm{H}_{10} \mathrm{TPPP}\right)$. Although it was known early in $1992,{ }^{59}$ coordination polymers containing $\mathrm{H}_{x}$ TPPP-based metalloligands were reported only recently.
Stock and co-workers employed a high-throughput method and synthesized a series of metal-organic frameworks using $\mathrm{Ni}\left(\mathrm{H}_{x} \mathrm{TPPP}\right)$ metalloporphyrins (Scheme $\left.7 \mathrm{f}\right)$ as the precursor. Compounds $\mathrm{M}\left(\mathrm{Ni}-\mathrm{H}_{6} \mathrm{TPPP}\right)\left(\mathrm{H}_{2} \mathrm{O}\right)[\mathrm{M}=\mathrm{Mn}$ (49), $\mathrm{Co}$ (50), Ni (51), $\mathrm{Cd}(52)]^{60}$ are isostructural, and the structure of $\mathrm{Ni}\left(\mathrm{Ni}-\mathrm{H}_{6} \mathrm{TPPP}\right)$ $\left(\mathrm{H}_{2} \mathrm{O}\right) \cdot 11 \mathrm{H}_{2} \mathrm{O}(51)$ is shown in Fig. 10 . $\mathrm{Ni}-\mathrm{H}_{6} \mathrm{TPPP}^{2-}$ acts as a pentadentate metalloligand, binding five equivalent Ni1 atoms via four phosphonate oxygen atoms, each from a different phosphonate group (Fig. 10a). The phosphonate oxygen $\mathrm{O} 1$ serves as $\mu_{3}$-O bridging two Ni1 atoms forming an edge-sharing $\left\{\mathrm{Ni}_{2} \mathrm{O}_{2}\right\}$ dimer (Fig. 10b). Each dimer is connected to eight Ni- $\mathrm{H}_{6} \mathrm{TPPP}^{2-}$ metalloligands and each $\mathrm{Ni}-\mathrm{H}_{6} \mathrm{TPPP}^{2-}$ links to four $\left\{\mathrm{Ni1}_{2} \mathrm{O}_{2}\right\}$ dimers, therefore constructing a $3 \mathrm{D}$ porous structure containing two kinds of rhombic channels with dimensions $2.8 \times 5.0$ and $3.8 \times 3.8 \AA$ (van der Waals radii accounted) or $5.5 \times 8.0$ and $7.0 \times 7.0 \AA$ (van der Waals radii not accounted) that host water molecules (Fig. 10c). Sorption measurements revealed that $\mathbf{5 1}$ shows the highest water uptake of $181 \mathrm{mg} \mathrm{g}^{-1}$. Moreover, it is stable in the $\mathrm{pH}$ range between 1 and 11 .

A dinuclear building unit is also found in compound $\mathrm{Zn}_{3}\left(\mathrm{Ni}-\mathrm{H}_{3} \mathrm{TPPP}\right)_{3} \cdot 9\left(\mathrm{CH}_{3}\right)_{2} \mathrm{NH}_{2} \cdot 3 \mathrm{DMF} \cdot 17 \mathrm{H}_{2} \mathrm{O}$ (53). ${ }^{61}$ Here the metalloligand $\mathrm{Ni}^{-} \mathrm{H}_{3} \mathrm{TPPP}^{5-}$ acts as a tetra-dentate ligand, binding to four $\mathrm{Zn}$ atoms (Fig. 10d). The $\mathrm{Zn}$ atoms have tetrahedral geometries, unlike the octahedral geometry of the $\mathrm{Ni}(\mathrm{II})$ ion in $\mathbf{5 1}$. The $\mathrm{Zn}$ atoms are doubly bridged by $\mathrm{O}-\mathrm{P}-\mathrm{O}$ units forming $\left\{\mathrm{Zn}_{2}(\mathrm{OPO})_{2}\right\}$ dimers (Fig. 10e). Each dimer is connected to six Ni- $\mathrm{H}_{3} \mathrm{TPPP}^{5-}$, while each $\mathrm{Ni}-\mathrm{H}_{3} \mathrm{TPPP}^{5-}$ is connected to three $\left\{\mathrm{Zn}_{2}(\mathrm{OPO})_{2}\right\}$ dimers. Although the connecting topology in $\mathbf{5 3}$ is quite different from that in 51, a 3D open framework containing rhombic channels is again constructed in $\mathbf{5 1}$ (Fig. 10f). The channel size is $c a$. $4.5 \times 10 \AA$ (van der Waals radii not accounted). The anionic framework is charge-balanced by $\left(\mathrm{CH}_{3}\right)_{2} \mathrm{NH}_{2}{ }^{+}$which, together with the solvent molecules, occupies the channel space. (a)

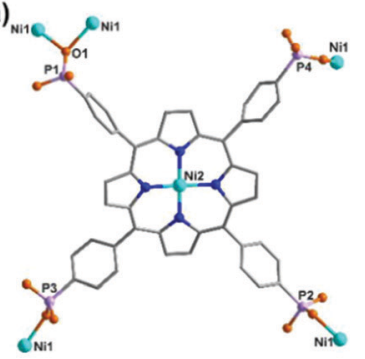

(d)

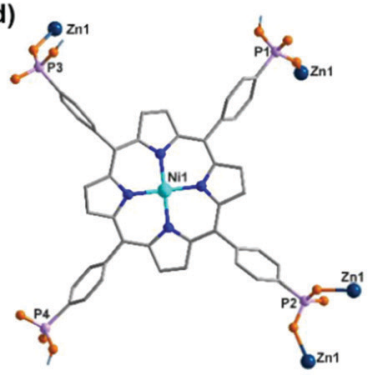

(b)

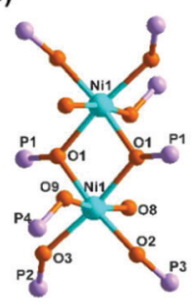

(e)

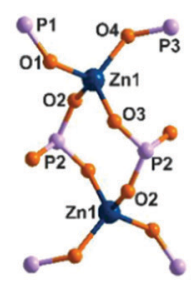

(c)

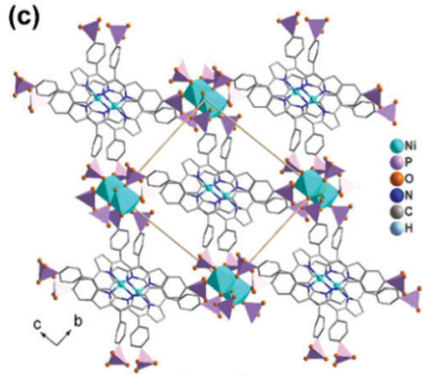

(f)

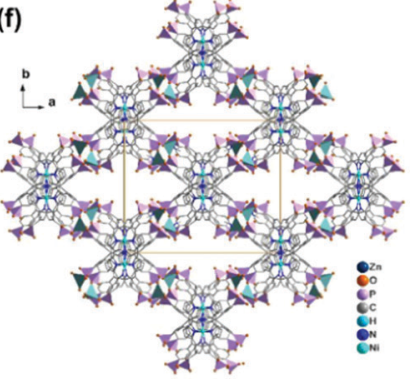

Fig. $10(a-c)$ The structure of compound 51: (a) coordination mode of Ni- $\mathrm{H}_{6} \mathrm{TPPP}^{2-}$, (b) dimeric building unit, (c) packing diagram. (d-f) The structure of compound 53: (d) coordination mode of $\mathrm{Ni}^{-} \mathrm{H}_{6} \mathrm{TPPP}^{2-}$, (e) dimeric building unit, (f) packing diagram. Adapted from ref. 60 and 61. 
Another example containing the $\mathrm{Ni}-\mathrm{H}_{x} \mathrm{TPPP}$ metalloligand is $\left[\mathrm{Co}_{2}\left(\mathrm{Ni}-\mathrm{H}_{4} \mathrm{TPPP}\right)\right] \cdot 2 \mathrm{DABCO} \cdot 6 \mathrm{H}_{2} \mathrm{O}(54$ or Co-CAU-36) $(\mathrm{DABCO}=$ 1,4-diazabicyclo[2.2.2] octane), $^{62}$ the structure of which was determined by single-crystal electron diffraction using continuous rotation electron diffraction (cRED) data collected at low

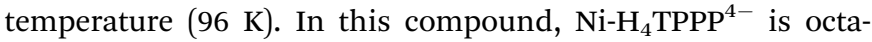
dentate, coordinating to eight Co atoms using eight of its twelve phosphonate oxygen atoms (Fig. 11a). The Co atom has a distorted tetrahedral geometry. The equivalent Co atoms are doubly bridged by phosphonate groups through corner-sharing of $\left\{\mathrm{CoO}_{4}\right\}$ and $\left\{\mathrm{PO}_{3} \mathrm{C}\right\}$ forming an inorganic chain (Fig. 11b). The chains are cross-linked by the $\mathrm{Ni}-\mathrm{H}_{4} \mathrm{TPPP}^{4-}$ moieties to form a 3D open framework with 1D rectangular channels generated along the $c$-axis (Fig. 11c). The channel has a pore diameter of $c a .9 \AA$ (van der Waals radii accounted) when taking the DABCO guest molecules into account, and a diameter of $c a .12 .5 \AA$ (van der Waals radii accounted) when the pores are empty.

Interestingly, a similar framework structure with rectangular channels is also observed for tetravalent metal compounds $\left[\mathrm{M}_{2}\left(\mathrm{Ni}-\mathrm{H}_{2} \mathrm{TPPP}\right)(\mathrm{OH} / \mathrm{F})_{2}\right] \cdot \mathrm{H}_{2} \mathrm{O}[\mathrm{M}=\mathrm{Zr}$ (55), Hf (56); (M-CAU30)]. ${ }^{63} 55$ and 56 are isostructural. Like that in 54, the metalloligand $\mathrm{Ni}-\mathrm{H}_{2} \mathrm{TPPP}^{6-}$ acts as an octa-dentate ligand, binding to eight $\mathrm{Zr}^{\mathrm{IV}}$ (or $\mathrm{Hf}^{\mathrm{IV}}$ ) ions (Fig. 11d). A significant difference between 55 and $\mathbf{5 4}$ is the coordination geometry of second metal ions, which is tetrahedral for Co(II) in $\mathbf{5 4}$ but octahedral for $\mathrm{Zr}(\mathrm{Iv})$ in 55. The adjacent $\mathrm{Zr}$ atoms are bridged not only by two phosphonate groups but also by $\mathrm{OH}^{-} / \mathrm{F}^{-}$anions, hence leading to an infinite chain containing corner-sharing $\left\{\mathrm{ZrO}_{6}\right\}$ octahedra (Fig. 11e). The chains are cross-linked by the $\mathrm{Ni}-\mathrm{H}_{2} \mathrm{TPPP}^{6-}$ ligands to form a 3D framework (Fig. 11f). The channel diameters are $1.3 \times 2.0 \mathrm{~nm}$ (van der Waals radii accounted). M-CAU-30 show the highest specific surface area among metal phosphonates of 1070 and $1030 \mathrm{~m}^{2} \mathrm{~g}^{-1}$ for 55 and 56, respectively, derived from the experimental data for the corresponding compounds contaminated with $\mathrm{ZrO}_{2}$ or $\mathrm{HfO}_{2}$ impurities. They are chemically stable in the $\mathrm{pH}$ range $0-12$ and thermally stable up to $420{ }^{\circ} \mathrm{C}$ in air. The remarkable stability of M-CAU-30 makes them promising candidates for many applications such as gas separation and storage, catalysis and proton conduction.

Yücesan, Zorlu and co-workers reported an alkali phosphonate MOF containing the $\mathrm{Cu}-\mathrm{H}_{4} \mathrm{TPPP}^{4-}$ metalloligand, formulated as $\left[\mathrm{Na}_{2}\left(\mathrm{Cu}-\mathrm{H}_{4} \mathrm{TPPA}\right)\right] \cdot\left(\mathrm{NH}_{2}\left(\mathrm{CH}_{3}\right)_{2}\right)_{2}(57) \cdot{ }^{64} 57$ crystallizes in a triclinic space group $P \overline{1}$. It also shows a $3 \mathrm{D}$ open framework structure with rectangular shaped channels (7.6 $\times 7.6 \AA$, van der Waals radii not accounted), composed of $\mathrm{Na}-\mathrm{O}-\mathrm{P}-\mathrm{O}$ inorganic chains and $\mathrm{Cu}-\mathrm{H}_{4} \mathrm{TPPP}^{4-}$ linkages. Each $\mathrm{Cu}-\mathrm{H}_{4} \mathrm{TPPP}^{4-}$ binds to eight $\mathrm{Na}^{\mathrm{I}}$ ions. The $\mathrm{Na}^{\mathrm{I}}$ ions are either four-coordinated (for Na1) or five-coordinated (for Na2), each of which is edge-shared with its equivalent ones forming $\left\{\mathrm{Na}_{2} \mathrm{O}_{2}\right\}$ or $\left\{\mathrm{Na}_{2} \mathrm{O}_{2}\right\}$ dimers. The dimers are connected via phosphonate oxygen and $\mathrm{O}-\mathrm{P}-\mathrm{O}$ units in an alternative manner, forming an infinite chain. These chains are crosslinked by $\mathrm{Cu}-\mathrm{H}_{4} \mathrm{TPPP}^{4-}$ metalloligands into a 3D framework (Fig. 12). After activation, the compound shows a surface area of $698 \mathrm{~m}^{2} \mathrm{~g}^{-1}$ which is dramatically larger than that of the other Na-MOFs, but close to that of $\left[\mathrm{Co}_{2}\left(\mathrm{Ni}-\mathrm{H}_{4} \mathrm{TPPP}\right)\right]$. $2 \mathrm{DABCO} \cdot 6 \mathrm{H}_{2} \mathrm{O}\left(700 \mathrm{~m}^{2} \mathrm{~g}^{-1}\right)$.

To summarize, metalloporphyrins with one or two esterified phosphonate groups form 1D chains with second metal ions, while those with four phosphonic acid groups form 3D open framework structures with different channel sizes. These MMPs show very high thermal and chemical stability and a large surface area, especially those containing tetravalent $\mathrm{Zr}^{\mathrm{IV}}$ and $\mathrm{Hf}^{\mathrm{IV}}$

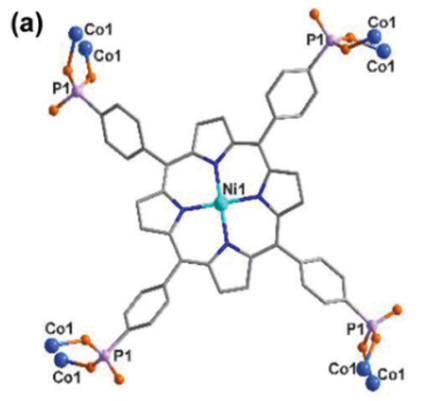

(d)

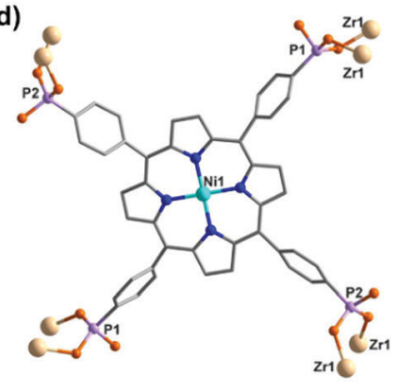

(b)

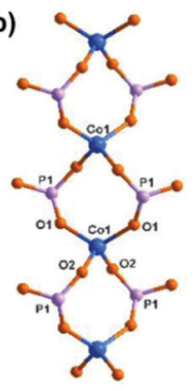

(e)

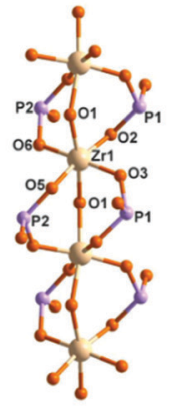

(c)

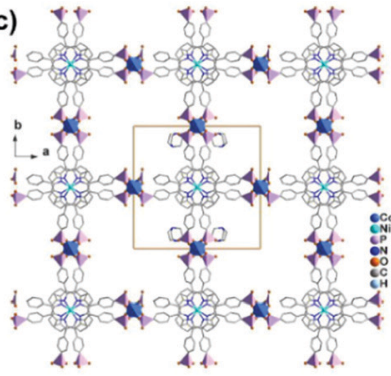

(f)

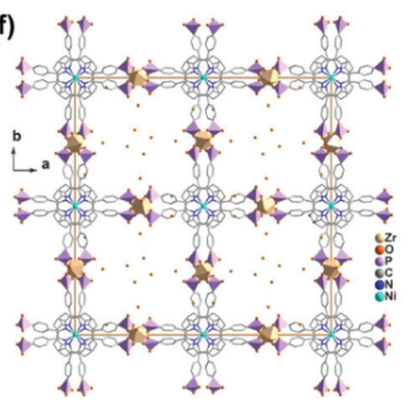

Fig. 11 (a-c) The structure of compound 54: (a) coordination mode of $\mathrm{Ni}_{-} \mathrm{H}_{6} \mathrm{TPPP}^{2-}$, (b) dimeric building unit, (c) packing diagram. (d-f) The structure of compound 55: (d) coordination mode of $\mathrm{Ni}_{-} \mathrm{H}_{6} \mathrm{TPPP}^{2-}$, (e) dimeric building unit, (f) packing diagram. Adapted from ref. 62 and 63. 


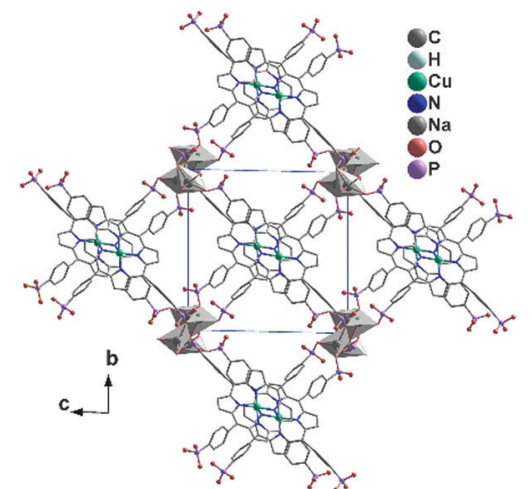

Fig. 12 Packing diagram of structure 57. Adapted from ref. 64.

ions. By retaining chemically transformable groups like esters in some of these porphyrin-based MMPs, there exist further opportunities to diversify their structures and functions via crystal to crystal transformations. All these features are remarkable for the development of functional MOFs for future applications.

\subsection{Cyclometalate or metal-polypyridine complexes as metalloligands}

Metalloligands such as cyclometalated Ir(III) complexes and $\mathrm{Ru}(\mathrm{II})$ polypyridine complexes are very attractive for constructing functional coordination polymers because they can act not only as a chromophore or luminophore but also as a reversible redox reaction centre. By using $\operatorname{Ir}(\mathrm{ppy})_{2}(\mathrm{bppH})(\mathrm{ppy}=$ 2-phenylpyridine, $\mathrm{bppH}_{2}=2$-pyridylphosphonic acid) as the metalloligand, we isolated isostructural heptanuclear $\operatorname{LnIr}_{6}$ clusters $\left[\operatorname{LnIr}_{6}(\mathrm{ppy})_{12}(\mathrm{bpp})_{2}(\mathrm{bppH})_{4}\right]\left(\mathrm{CF}_{3} \mathrm{SO}_{3}\right) \cdot x \mathrm{H}_{2} \mathrm{O}[\mathrm{Ln}=\mathrm{Eu}(\mathbf{5 8})$, $\mathrm{Tb}$ (59), Dy (60), Er (61), Yb (62); ppy = 2-phenylpyridine; bpp = 2pyridylphosphonate]..$^{65}$ The clusters are packed in the lattice, forming a supramolecular network containing channels in the $a$ - and $c$-directions, where the lattice water molecules and the $\mathrm{CF}_{3} \mathrm{SO}_{3}{ }^{-}$ anions reside (Fig. 13). The two edge distances of the quadrilateral window in the $a b$ plane are 15.877 and $16.958 \AA$, respectively. However, coordination polymers incorporating Ir(III) cyclometalatephosphonate metalloligands have not been documented.

MMPs containing $\mathrm{Ru}(\mathrm{II})$-polypyridine metalloligands are also rare. The only examples are $\mathrm{Ln}_{3}\left(\mathrm{H}_{2} \mathrm{O}\right)_{9}\left[\mathrm{Ru}\left(4,4^{\prime} \text {-dpbpy }\right)_{3} \mathrm{H}_{5.5}\right]_{2}$. $n \mathrm{H}_{2} \mathrm{O}$ [Ln $\left.=\mathrm{La}^{\mathrm{III}}(\mathbf{6 3}), \operatorname{Pr}^{\mathrm{III}}(\mathbf{6 4})\right]{ }^{66}$ where $\mathrm{dpbpyH}_{4}$ is $2,2^{\prime}$ bipyridinyl-4,4'-diphosphonic acid (Scheme 8). The two compounds
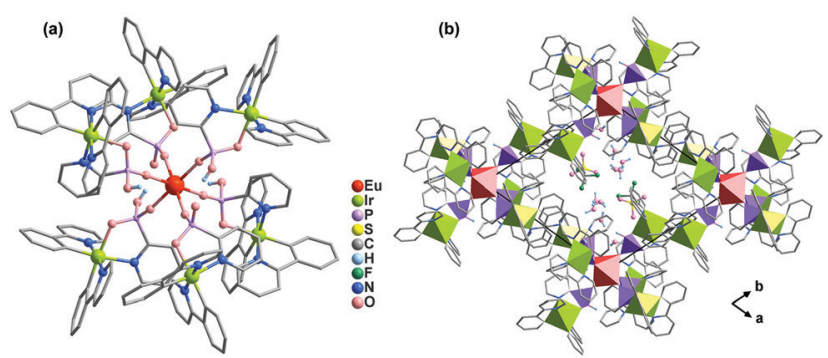

Fig. 13 (a) The heptanuclear cluster of 58. (b) Packing diagram of $\mathbf{5 8}$ viewed along the $c$-axis. Color codes: $\mathrm{EuO}_{6}$, red; $\operatorname{IrC}_{2} \mathrm{~N}_{3} \mathrm{O}$, yellow green; $\mathrm{PO}_{3} \mathrm{C}$, purple. Adapted from ref. 65.
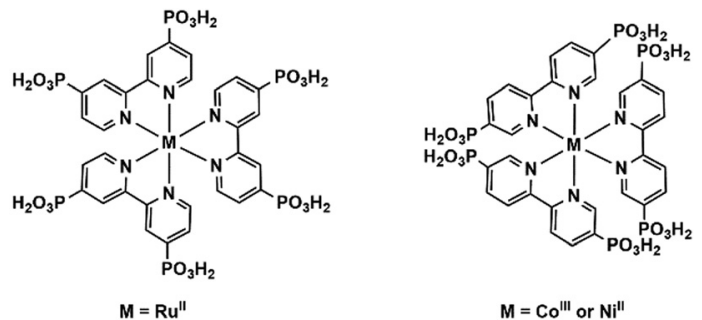

Scheme 8 Molecular structures of metalloligands $\mathrm{Ru}^{\prime \prime}\left(4,4^{\prime}-\mathrm{dpbpyH}_{4}\right)_{3}{ }^{2+}$ and $\left[M\left(5,5^{\prime}-\mathrm{dpbpyH}_{4}\right)_{3}\right]^{n+}$.
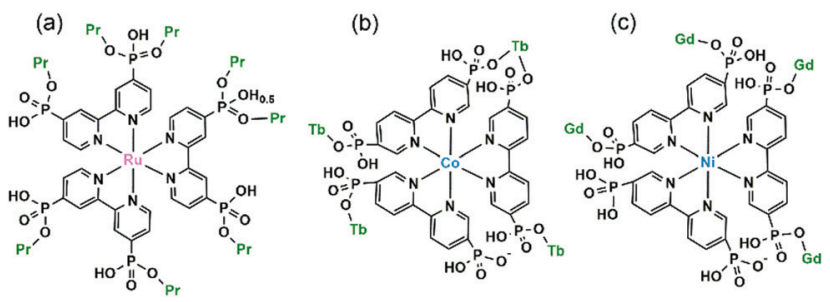

Scheme 9 Coordination modes of metalloligands $\mathrm{Ru}^{\prime \prime}\left(4,4^{\prime}-\mathrm{dpbpyH}_{4}\right)_{3}{ }^{2+}$ and $\left[M\left(5,5^{\prime}-\mathrm{dpbpyH}_{4}\right)_{3}\right]^{n+}$

are isostructural. Single crystal structural analysis of $\mathbf{6 4}$ reveals that it crystallizes in monoclinic space group $P 2_{1} / n$. There are two kinds of Pr atoms in the structure. The Pr1 atom is coordinated by five phosphonate oxygen atoms and three water molecules to form a square antiprismatic geometry. The disordered $\operatorname{Pr} 2$ atom (half/half) is surrounded by five phosphonate oxygen atoms and three water molecules. $\mathrm{Ru}^{\mathrm{II}}\left(4,4^{\prime} \text {-dpbpy }\right)_{3} \mathrm{H}_{5.5}{ }^{1.5-}$ serves as an octa-dentate metalloligand, binding to eight Pr atoms via eight of its eighteen phosphonate oxygen atoms (Scheme 9a). Two of the six phosphonate groups are involved in bridging the Pr1 atoms into $\left\{\mathrm{Pr}_{2}(\mathrm{OPO})_{2}\right\}$ dimers. The remaining four phosphonate groups are involved in coordination with one Pr1 and three Pr2 atoms. As a result, the $\operatorname{Pr}$ atom and $\left\{\operatorname{Pr}_{2}(\mathrm{OPO})_{2}\right\}$ dimers are cross-linked by the $\left[\mathrm{Ru}\left(4,4^{\prime} \text {-dpbpy }\right)_{3} \mathrm{H}_{5.5}\right]^{4.5-}$ metalloligands forming a threedimensional open framework (Fig. 14). The framework contains two kinds of narrow porous channels along the $b$-axis with dimensions of $c a .4 .4 \times 6.0 \AA$ and $3.2 \times 4.6 \AA$ (van der Waals radii not accounted).

The central metal ions in $\mathrm{Ru}^{\mathrm{II}}(\mathrm{bpy})_{3}$-based metalloligands can be substituted by other metal ions such as $\mathrm{Co}(\mathrm{II})$ or Ni(II).

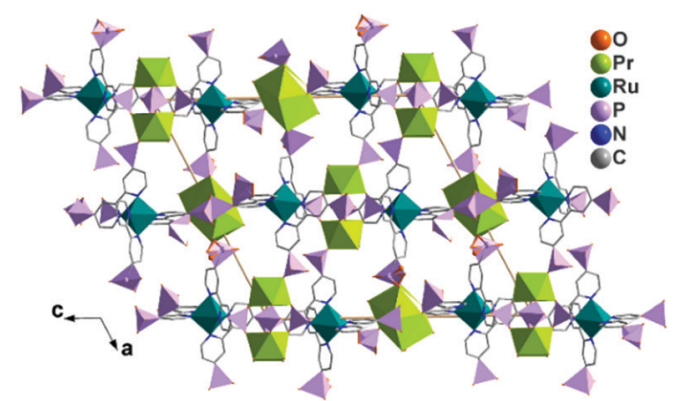

Fig. 14 Packing diagram of structure 64. Adapted from ref. 66. 
Rentschler and co-workers employed 2,2'-bipyridinyl-5, $5^{\prime}$ diphosphonic acid $\left(5,5^{\prime}-\mathrm{dpbpyH}_{4}\right)$ and obtained $\left[\mathrm{LnCo}^{\mathrm{III}}\left(5,5^{\prime}-\right.\right.$ $\left.\left.\mathrm{dpbpyH}_{2}\right)_{3}\left(\mathrm{H}_{2} \mathrm{O}\right)_{2}\right] \cdot 6.5 \mathrm{H}_{2} \mathrm{O}\left[\mathrm{Ln}=\mathrm{Gd}^{\mathrm{III}}(65)\right.$, Dy ${ }^{\mathrm{III}}(66)$ and $\mathrm{Tb}^{\mathrm{III}}$ (67) $]$ and $\left[\mathrm{GdNi}^{\mathrm{II}}\left(5,5^{\prime}-\mathrm{dpbpyH}_{2}\right)_{3}\left(\mathrm{H}_{2} \mathrm{O}\right)_{3}\right] \mathrm{NaCl} \cdot 6 \mathrm{H}_{2} \mathrm{O}(68),{ }^{67}$ where $\mathrm{M}\left(5,5^{\prime}-\mathrm{dpbpyH}_{4}\right)_{3} \quad\left(\mathrm{M}=\mathrm{Co}^{\mathrm{III}}, \mathrm{Ni}^{\mathrm{II}}\right)$ act as metalloligands (Scheme 8). Compounds 65-67 are isostructural, crystallizing in the space group $C 2 / c$. The lanthanide atom is sevencoordinated with a capped trigonal prismatic geometry, which is rare for lanthanide ions. The seven sites are occupied by five oxygen atoms from separate phosphonate groups of four $\mathrm{Co}\left(5,5^{\prime}-\mathrm{dpbpyH}_{2}\right)_{3}{ }^{3-}$ and two water molecules. All phosphonates are mono protonated in the $\mathrm{Co}\left(5,5^{\prime}-\mathrm{dpbpyH}_{2}\right)_{3}{ }^{3-}$ unit, which serves as a penta-dentate metalloligand and links four equivalent lanthanide atoms through its five phosphonate oxygen atoms (Scheme 9b). Therefore, each $\mathrm{Ln}(\mathrm{III})$ is connected by four $\mathrm{Co}\left(5,5^{\prime}-\mathrm{dpbpyH}_{2}\right)_{3}{ }^{3-}$ units and vice versa, leading to a two-dimensional layer (Fig. 15a). The uncoordinated phosphonate groups are pendant on the two sides of the layer, and are involved in the interlayer hydrogen bonds.

Interestingly, different connectivity and dimensionality are observed in 68 when the metal center of $\mathrm{Co}^{\mathrm{III}}\left(5,5^{\prime}-\mathrm{dpbpyH}_{2}\right)_{3}{ }^{3-}$ is replaced by the divalent $\mathrm{Ni}$ ion. In this case, each Gd atom in 68 again has a capped trigonal prismatic coordination. But the seven coordination sites are filled with only four phosphonate oxygen atoms and three water molecules. Another significant difference for the metalloligand $\mathrm{Ni}\left(5,5^{\prime}-\mathrm{dpbpyH}_{2}\right)_{3}{ }^{4-}$ is that it is tetra-dentate, binding to four Gd atoms via its four phosphonate groups. The two phosphonate groups of one $5,5^{\prime}-\mathrm{dpbpyH}_{2}$ remain uncoordinated (Scheme 9c). As a result, each Gd is connected to four $\mathrm{Ni}\left(5,5^{\prime}-\mathrm{dpbpyH}_{2}\right)_{3}{ }^{4-}$ and vice versa. Although this kind of connectivity is similar to that in 67 , the geometry of $\mathrm{GdNi}_{4}$ in 68 differs from that of $\mathrm{TbCo}_{4}$ in 67 . The four $\mathrm{Ni}$ atoms in $\mathrm{GdNi}_{4}$ are arranged closer to a trigonal pyramid, unlike the (a)

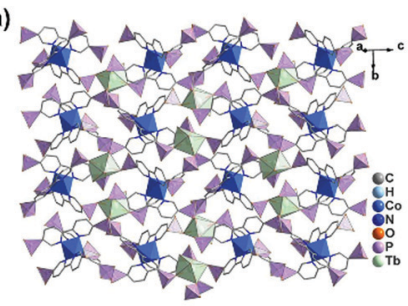

(c)

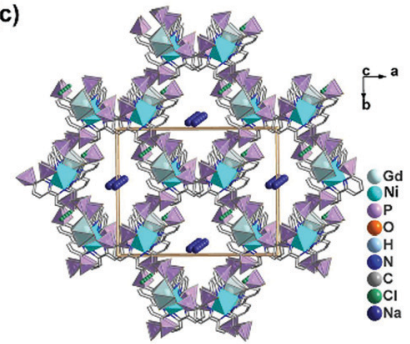

(b)

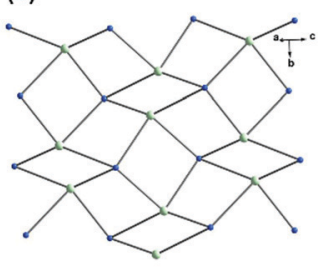

(d)

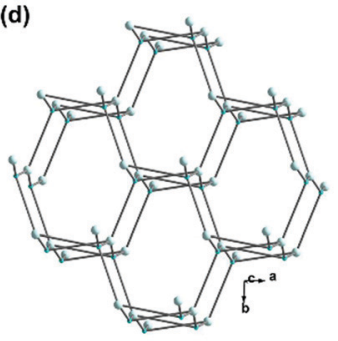

Fig. 15 (a) One layer and (b) layer topology of structure 67. (c) Packing diagram and framework topology of structure 68. The topologies in (b) and (d) are presented by the connections between the metalloligand centers and the lanthanide atoms. Adapted from ref. 67. four Co atoms in $\mathrm{TbCo}_{4}$ which are closer to a square plane. Thus a three-dimensional open framework is constructed in $\mathbf{6 8}$ which contains rhombic channels along the $c$-axis with dimensions of ca. $6.4 \times 10.8 \AA$ (van der Waals radii not accounted) (Fig. 15c). The sodium and chloride ions are occupying the space within the channels.

To summarize, the use of cyclometalate or metal-polypyridine complexes as metalloligands to construct MMPs brings not only internal functions such as luminescence and redox but also more diverse structures. The cyclometalated Ir(III) complex containing 2-pyridylphosphonate was used to assemble a series of $\operatorname{LnIr}_{6}$ heptanuclear species. On the other hand, $M(b p y)_{3}{ }^{-}$ based ligands were employed to build MMPs with 2D layer and 3D open framework structures. Moreover, the phosphonate groups in bipyridine can be placed in different substitution positions. The varied number of phosphonate groups in these metalloligands together with their different pre-organized conformation offers more coordination modes, leading to MMPs with different architectures. Although only a handful of examples have been given in this aspect, the result is encouraging in exploring new MMPs based on cyclometalate or metal-polypyridine complexes with versatile structures and interesting properties.

\section{Properties and applications}

Metal-metalloligand phosphonates offer several advantages over other metal phosphonates not only in structural complexity but also in functions. The presence of different metal ions could affect their physical properties and, in some cases, manipulate the property synergistically. The immobilization of the pre-organized functional metalloligand within metal phosphonate frameworks also provides opportunities in exploring new materials with high thermal and water stability, interesting magnetic, optical, and proton conductive properties and efficient heterogeneous catalytic performance.

\subsection{Magnetic and optical properties}

For metal-metalloligand phosphonates, the magnetic moment can originate from either the metalloligand, or the second metal ion, or both. Typical paramagnetic metalloligands are metal-metal bonded $\mathrm{Ru}_{2}$ (hedp) ${ }_{2}{ }^{n-}$ species with paddlewheel structures. Early studies on diruthenium tetracarboxylates have demonstrated that the homovalent $\mathrm{Ru}_{2}^{\mathrm{II}, \mathrm{II}}\left(\mathrm{O}_{2} \mathrm{CR}\right)_{4}$ and mixedvalent $\left[\mathrm{Ru}_{2}^{\mathrm{II}, \mathrm{III}}\left(\mathrm{O}_{2} \mathrm{CR}\right)_{4}\right]^{+}$contain two $(S=1)$ and three unpaired electrons $(S=3 / 2)$ in electron configurations of $\sigma^{2} \pi^{4} \delta^{2}\left(\pi^{*}\right)^{2}\left(\delta^{*}\right)^{2}$ and $\sigma^{2} \pi^{4} \delta^{2} \pi^{* 2} \delta^{* 1}{ }^{68}$ Accordingly, the ground states for $\mathrm{Ru}_{2}^{\mathrm{II}, \mathrm{II}}\left(\right.$ hedp) ${ }_{2}{ }^{4-}$ and $\mathrm{Ru}_{2}{ }^{\mathrm{II}, \mathrm{III}}(\text { hedp })_{2}{ }^{3-}$ are $S=1$ and $3 / 2$, respectively. As already described, a series of MMPs containing $\mathrm{Ru}_{2}{ }^{5+}$ units have been obtained. They show large and positive zero-field splitting (ZFS) with the $D$ parameters being $78.3-103.2 \mathrm{~cm}^{-1}$ (Table 1). The interactions between the $\mathrm{Ru}_{2}$ dimers are usually weak, which can be ferromagnetic as observed in layer compounds 1-2, or antiferromagnetic as observed in $\mathrm{Ln}-\mathrm{Ru}_{2}$ frameworks. The introduction of the lanthanide ion into the $\mathrm{Ru}_{2}$ system can 
bring an additional magnetic source and multiple exchange pathways. For $\mathrm{Dy}-\mathrm{Ru}_{2}$ and $\mathrm{Yb}-\mathrm{Ru}_{2}$ compounds 17 and 18, fieldinduced slow magnetic relaxation characteristic of single molecule magnet (SMM) behaviour was observed. But no peaks of inphase and out-of-phase ac signals appear down to $2 \mathrm{~K}$. Lanthanide complexes are well known to be promising systems for SMMs owing to their large single-ion magnetic anisotropy arising from the unquenched orbital angular momentum and strong spin-orbit coupling. ${ }^{69}$ The observation of magnetization relaxation in $\mathbf{1 7}$ and $\mathbf{1 8}$ can be mainly attributed to the presence of Kramers ions Dy ${ }^{\mathrm{III}}$ or $\mathrm{Yb}^{\mathrm{III}}$. Though the $\mathrm{Ru}_{2}{ }^{5+}$ dimer also shows strong spin-orbit coupling, its contribution to magnetic relaxation remains unclear.

The magnetic properties of one metal ion could be affected by another metal ion in MMPs. An interesting example is $\left[\mathrm{LaCo}(\right.$ notp $\left.)\left(\mathrm{H}_{2} \mathrm{O}\right)_{4}\right] \cdot n \mathrm{H}_{2} \mathrm{O}(\mathbf{2 2})^{30}$ which is diamagnetic with the octahedral $\mathrm{Co}^{\mathrm{III}}$ ion in a low spin state. It has a layer structure where the metalloligand $\operatorname{Co}(\text { notp })^{3-}$ is quadra-dentated binding to four $\mathrm{La}^{\mathrm{III}}$ ions. Each La atom is eight-coordinated by four phosphonate oxygen atoms from four $\mathrm{Co}(\text { notp })^{3-}$ and four water molecules. Thermal treatment up to $220{ }^{\circ} \mathrm{C}$ causes the release of both lattice and coordination water molecules. However, the coordination number of La remains the same as confirmed by EXAFS measurements. The vacant sites of La are filled with the phosphonate oxygen atoms from neighbouring $\mathrm{Co}(\text { notp })^{3-}$, leading to the elongation of the Co-O bond length. The elongation of the Co-O length weakens the ligand field strength and stabilizes the high-spin $\mathrm{Co}^{\mathrm{II}}$. A thermally induced electron transfer occurs with the switching of the cobalt oxidation state, from diamagnetic low-spin $\mathrm{Co}^{\mathrm{III}}$ to paramagnetic high-spin $\mathrm{Co}^{\text {II }}$ (Fig. 16). Moreover, the dehydrated $\mathrm{H}\left[\mathrm{hs}^{\mathrm{C}-\mathrm{Co}^{\mathrm{II}} \mathrm{La}}{ }^{\mathrm{III}}\right.$ (notp)] can turn back to the original [ls$\mathrm{Co}^{\mathrm{III}} \mathrm{La}^{\mathrm{III}}\left(\right.$ notp) $\left.\left(\mathrm{H}_{2} \mathrm{O}\right)_{4}\right] \cdot n \mathrm{H}_{2} \mathrm{O}$ upon rehydration in air. Compound 22 serves as a good example of metal-organic systems showing dehydration induced synergistic change of the coordination spheres of two kinds of metal ions linked by a polyazamacrocycle ligand and its impact on the magnetic properties.

As a comparison, the $\mathrm{Ln}^{\mathrm{III}}-\mathrm{Fe}^{\mathrm{III}}$ and $\mathrm{Ca}^{\mathrm{II}}-\mathrm{Co}^{\mathrm{III}}$ compounds 24-28 based on metalloligands $\mathrm{M}(\text { notp })^{3-}(\mathrm{M}=\mathrm{Fe}, \mathrm{Co})$ cannot undergo such valence change. This can be explained by the fact that the oxidation state of $\mathrm{Fe}^{\mathrm{III}}$ is not so sensitive to the

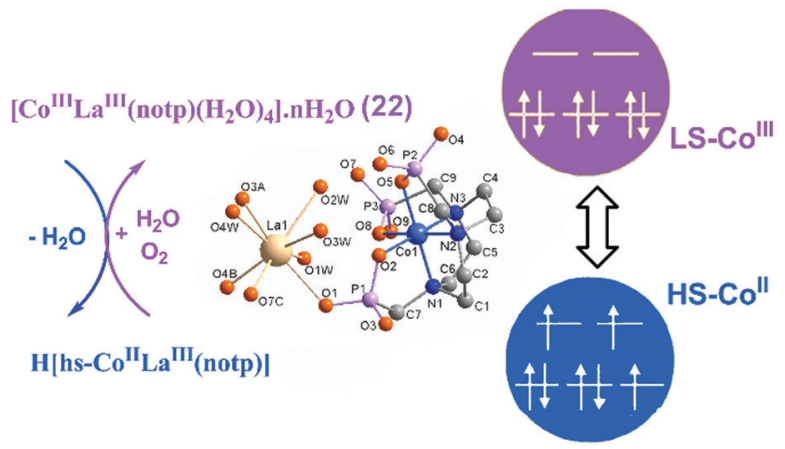

Fig. 16 The scheme of the valence change between 22 and $H$ [hsCo"La"'(notp)]. Adapted from ref. 30. ligand field, the coordination number of $\mathrm{Ca}^{\mathrm{II}}$ is less than that of $\mathrm{La}^{\mathrm{III}}$, and the $\mathrm{Ca}-\mathrm{O}$ bonds are weaker than $\mathrm{La}-\mathrm{O}$ bonds. By incorporating paramagnetic $\mathrm{IrCl}_{6}{ }^{2-}$ as a counter-anion, $\left[\mathrm{CaCo}_{2}\left(\text { notpH }_{3}\right)_{2}\left(\mathrm{H}_{2} \mathrm{O}\right)_{2}\right]\left(\mathrm{IrCl}_{6}\right) \cdot 4 \mathrm{H}_{2} \mathrm{O}$ (34) exhibits slow magnetic relaxation originating from isolated $\mathrm{Ir}^{\mathrm{IV}} \mathrm{Cl}_{6}{ }^{2-}$ species. ${ }^{35}$

Paramagnetic materials can be potential contrast agents (CAs) for magnetic resonance imaging (MRI). However, most of the research work has been focused on mononuclear $\mathrm{Gd}^{\mathrm{III}}$ complexes using polyazamacrocycle derivatives as ligands due to their high stability in aqueous solution. Maspoch and co-workers immobilized $\mathrm{Gd}^{\mathrm{III}}$ ions in the framework structure of $\left[\mathrm{GdCu}\left(\operatorname{dotpH}_{4}\right) \mathrm{Cl}\right] \cdot 4.5 \mathrm{H}_{2} \mathrm{O}(37),{ }^{37}$ which is stable in physiological saline solution and cell culture media. This material can be made into colloidal nanoparticles and shows interesting relaxometric properties with $r_{1}$ at a high field $(500 \mathrm{MHz})$ of $5 \mathrm{mM}^{-1} \mathrm{~s}^{-1}$ and a maximum $r_{1}=15 \mathrm{mM}^{-1} \mathrm{~s}^{-1}$ at $40 \mathrm{MHz}$. Furthermore, it can be used in a broad $\mathrm{pH}$ range, and the performance increases with temperature.

Reports on optically active MMPs are quite limited. For those containing metalloporphyrins, their UV-visible absorption spectra usually show a strong Soret band located at 410-440 nm ( $\mathrm{S}_{0} \rightarrow \mathrm{S}_{2}$ transition) and less intensive $\mathrm{Q}$ bands centered at 520-650 nm ( $\mathrm{S}_{0} \rightarrow \mathrm{S}_{1}$ transition). ${ }^{50-52,56,57,63}$ Heptanuclear clusters $\left[\operatorname{LnIr}_{6}(\mathrm{ppy})_{12}(\mathrm{bpp})_{2}(\mathrm{bppH})_{4}\right]\left(\mathrm{CF}_{3} \mathrm{SO}_{3}\right) \cdot x \mathrm{H}_{2} \mathrm{O}$ $[\mathrm{Ln}=\operatorname{Dy}(60), \operatorname{Er}(61), \mathrm{Yb}(62)]^{65}$ are multifunctional materials showing both phosphorescence originating from the cyclometalated Ir(III) component and field-induced single molecule magnet behaviour arising from the anisotropic lanthanide ions. Compounds $\mathrm{Ln}_{3}\left(\mathrm{H}_{2} \mathrm{O}\right)_{9}\left[\mathrm{Ru}\left(4,4^{\prime} \text {-dpbpy }\right)_{3} \mathrm{H}_{5.5}\right]_{2} \cdot n \mathrm{H}_{2} \mathrm{O}\left[\mathrm{Ln}=\mathrm{La}^{\mathrm{III}}\right.$ (56), $\operatorname{Pr}^{\mathrm{III}}$ (57)] provide rare examples of MMPs incorporating the luminescent $\mathrm{Ru}(\mathrm{II})$ polypyridine metalloligand. ${ }^{66}$ Interestingly, they exhibit a two-step vapochromism triggered by humidity. The triplet metal-to-ligand charge-transfer $\left({ }^{3} \mathrm{MLCT}\right)$ emission is blue-shifted on increasing the relative humidity (RH) in the low $\mathrm{RH}$ region, and red-shifted in the high $\mathrm{RH}$ region, resulting in the highest-energy ${ }^{3}$ MLCT emission at medium RH. The origin is ascribed to the water-adsorption triggered reconstruction of the porous structure and the proton release from the metalloligand to the water filled channels.

\subsection{Proton conductive properties}

Proton conductive materials play critical roles in many renewable energy and electronics technologies. ${ }^{70}$ Metal phosphonates are promising candidates owing to their high thermal and water stability, their ability to provide phosphonic acid groups as the proton source within extensive H-bond networks and their insulating nature, which are essential for high performance proton conductors. ${ }^{13}$ Since the number of MMPs is quite limited, only a few of them have been subjected to proton conductivity measurements. As shown in Tables 2 and 3, most compounds show conductivity in the range of $10^{-7}-10^{-4} \mathrm{~S} \mathrm{~cm}^{-1}$ at $95 \% \mathrm{RH}$ and $25{ }^{\circ} \mathrm{C}$. The conductivity can increase with increasing temperature, reaching $10^{-3} \mathrm{~S} \mathrm{~cm}^{-1}$ as observed for compound $\mathbf{5 3}$ at $90 \% \mathrm{RH}$ and $80{ }^{\circ} \mathrm{C}$.

It is interesting to observe the enhancement of proton conductivity of $\left[\mathrm{CoLa}(\operatorname{notpH})\left(\mathrm{H}_{2} \mathrm{O}\right)_{6}\right] \mathrm{ClO}_{4} \cdot 5 \mathrm{H}_{2} \mathrm{O} \quad(23)^{31}$ via 
in situ solid state phase transition. This compound is closely related to $\left[\mathrm{CoLa}\left(\right.\right.$ notp) $\left.\left(\mathrm{H}_{2} \mathrm{O}\right)_{4}\right] \cdot n \mathrm{H}_{2} \mathrm{O}$ (22) except for one phosphonate group protonated and hence an extra perchloride anion for charge compensation. Proton conductivity measurements on pellets of the powder samples of 22 and 23 show identical conductivity at $95 \% \mathrm{RH}$ and $25{ }^{\circ} \mathrm{C}$, being $3.0 \times 10^{-6}$ and $3.5 \times 10^{-6} \mathrm{~S} \mathrm{~cm}^{-1}$, respectively. Remarkably, 23 undergoes a solid state phase transition at $45{ }^{\circ} \mathrm{C}$ and $93 \% \mathrm{RH}$, forming a new phase $\left(\mathrm{H}_{3} \mathrm{O}\right)\left[\mathrm{CoLa}(\right.$ notp $\left.)\left(\mathrm{H}_{2} \mathrm{O}\right)_{4}\right] \mathrm{ClO}_{4} \cdot x \mathrm{H}_{2} \mathrm{O}$ which has the same layer structure as that of 22 but with additional hydronium ions and $\mathrm{ClO}_{4}{ }^{-}$anions between the neutral layers. Consequently, this new phase shows an enhanced proton conductivity of $4.2 \times 10^{-5} \mathrm{~S} \mathrm{~cm}^{-1}$ at $25{ }^{\circ} \mathrm{C}$ and $95 \% \mathrm{RH}$, one order of magnitude higher than that of $22\left(3.00 \times 10^{-6} \mathrm{~S} \mathrm{~cm}^{-1}\right)$ and $23\left(3.50 \times 10^{-6} \mathrm{~S} \mathrm{~cm}^{-1}\right)$.

The single crystal proton conductivity measurement can offer a chance to understand the proton transport mechanism. We used a single crystal of $\left[\mathrm{CoCa}\left(\right.\right.$ notpH $\left.\left._{2}\right)\left(\mathrm{H}_{2} \mathrm{O}\right)_{2}\right] \mathrm{ClO}_{4} \cdot 4 \mathrm{H}_{2} \mathrm{O}$ $(28)^{33}$ for AC impedance measurements. The result demonstrates that the [010] direction of H-bond extension is the preferred proton conduction pathway showing the highest conductivity of $1.00 \times 10^{-3} \mathrm{~S} \mathrm{~cm}^{-1}$ at $25{ }^{\circ} \mathrm{C}$ and $95 \% \mathrm{RH}$. On the other hand, the [20-1] direction, which involves the phosphonate oxygen atoms in the $\mathrm{H}$-bond network, shows the lowest conductivity of $4.35 \times 10^{-8} \mathrm{~S} \mathrm{~cm}^{-1}$ at $25{ }^{\circ} \mathrm{C}$ and $95 \% \mathrm{RH}$. Moreover, compound $\mathbf{2 8}$ experiences a reversible humidity dependent SC-SC structural transformation forming $\left[\mathrm{CoCa}\left(\right.\right.$ notpH $\left.\left._{2}\right)\left(\mathrm{H}_{2} \mathrm{O}\right)_{2}\right] \mathrm{ClO}_{4} \cdot 2 \mathrm{H}_{2} \mathrm{O}(29)$ below $70 \% \mathrm{RH}$ at room temperature with the continuous $\mathrm{H}$-bond network interrupted (Fig. 17a and b). The structural transformation leads to a drastic decrease in proton conductivity by $\sim 5$ orders of magnitude (Fig. 17c). The process is reversible and the response is quick (Fig. 17d), and thus the material can be used as an impedance humidity sensor for future applications.
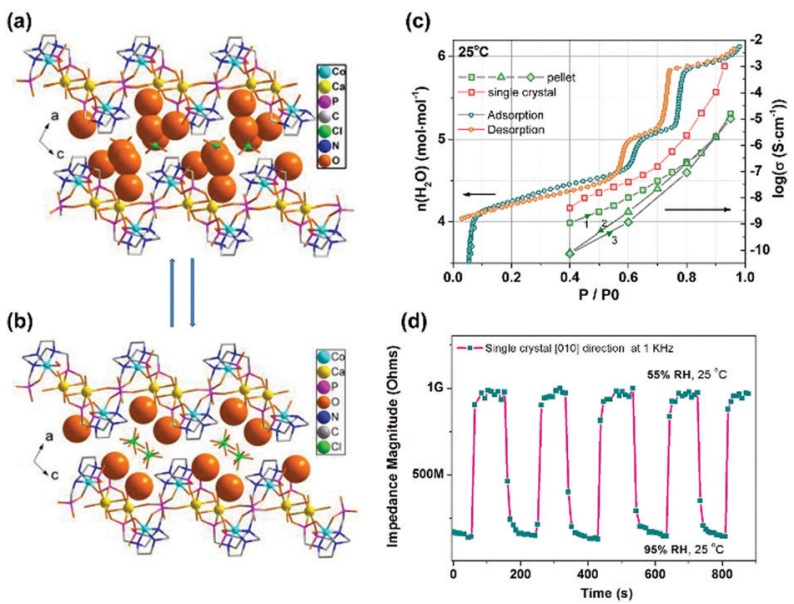

Fig. 17 (a and b) Packing diagrams of structures $\left[\mathrm{CaCo}\left(\mathrm{notpH}_{2}\right)\right.$ $\left.\left(\mathrm{H}_{2} \mathrm{O}\right)_{2}\right]\left(\mathrm{ClO}_{4}\right) \cdot 4 \mathrm{H}_{2} \mathrm{O}\left(\right.$ 28) (a) and $\left[\mathrm{CaCo}\left(\right.\right.$ notpH $\left.\left.\mathrm{H}_{2}\right)\left(\mathrm{H}_{2} \mathrm{O}\right)_{2}\right]\left(\mathrm{ClO}_{4}\right) \cdot 2 \mathrm{H}_{2} \mathrm{O}$ (29) (b). (c) Proton conductivity and adsorption isotherms of 28. (d) Impedance response and recovery time to $\mathrm{RH}$ variation between $55 \%$ and $95 \%$ for a single crystal of $\mathbf{2 8}$ along the [010] direction. Reprinted with permission from ref. 33. Copyright 2015, American Chemical Society.
To increase the proton conductivity of MMPs, one way is to increase the concentration of protons within the extensive H-bond network by providing more protonated phosphonate groups or acidic counterions. Another way is to produce composites by introducing salts into the framework or combine the MMP with suitable polymers. All these remain to be further explored.

\subsection{Catalytic properties}

MMPs can rationally immobilize catalytically active metal sites within the robust frameworks. Metalloporphyrins are prominent candidates for catalysis. Although the catalytic properties of MOFs containing metalloporphyrins have been well-explored, ${ }^{71}$ those of MMPs still remain rarely described due to the limited examples of MMPs. Manganese porphyrins $\mathrm{Mn}$ (porphyrin)Cl are active homogeneous catalysts for many oxidation reactions with $\mathrm{H}_{2} \mathrm{O}_{2}$ as the oxidizing agent in the presence of nitrogen base cocatalysts. By functionalizing manganese porphyrin with four phosphonate groups, Bujoli and co-workers reported the first examples of insoluble zinc phosphonate hybrid materials incorporating manganese porphyrins. ${ }^{72}$ They act as efficient heterogeneous oxidation catalysts in the epoxidation of cyclooctene with PhIO showing similar yields to their mononuclear precursor. Moreover, these catalysts show a different behaviour from their homogeneous counterparts in the competitive hydroxylation of alkane mixtures using PhIO as the oxidant, attributed to shape selectivity imposed by the phosphonate support. ${ }^{73}$

The introduction of chirality into catalytically active MMPs can extend their application in enantioselective catalysis. Lin and co-workers designed and synthesized a series of chiral porous zirconium phosphonates embedding enantiopure and catalytically active $\mathrm{Ru}$ species (Scheme 10). Compounds $\left[\mathrm{Zr}\left\{\mathrm{Ru}\left(\mathrm{L}^{3}\right)(\mathrm{DMF})_{2} \mathrm{Cl}_{2}\right\}\right] \cdot 2 \mathrm{MeOH}$ and $\left[\mathrm{Zr}\left\{\mathrm{Ru}\left(\mathrm{L}^{4}\right)(\mathrm{DMF})_{2} \mathrm{Cl}_{2}\right\}\right]$. $2 \mathrm{MeOH}$ are found to be highly active catalysts for asymmetric hydrogenation of $\beta$-ketoesters. ${ }^{74} \mathrm{Zr}\left[\mathrm{Ru}\left(\mathrm{L}^{3}\right)(\mathrm{DPEN}) \mathrm{Cl}_{2}\right] \cdot 4 \mathrm{H}_{2} \mathrm{O}$ and $\mathrm{Zr}\left[\mathrm{Ru}\left(\mathrm{L}^{4}\right)(\mathrm{DPEN}) \mathrm{Cl}_{2}\right] \cdot 4 \mathrm{H}_{2} \mathrm{O}$ are excellent catalysts for enantioselective hydrogenation of unfunctionalized aromatic ketones. $^{75}$
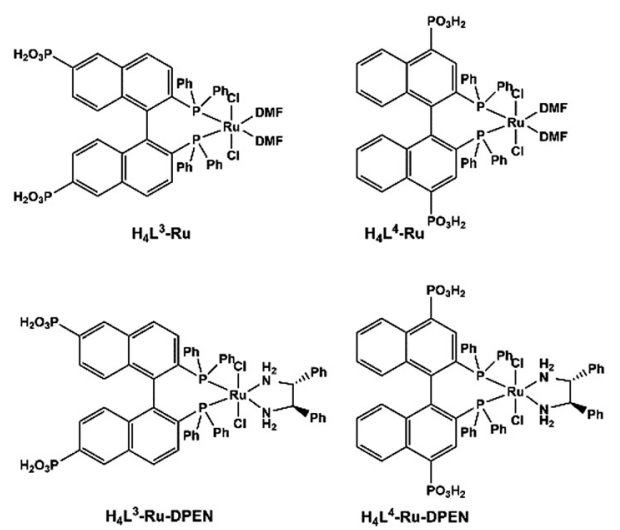

Scheme 10 Molecular structures of Ru complexes of binaphthalenebisphosphonic acids. Reprinted with permission from ref. 10f. Copyright 2020, Springer Nature. 


\section{Summary and outlook}

In this feature article, we have presented the current status of metal-metalloligand phosphonates (MMPs) from syntheses, structures to properties. It is clear that using the pre-formed metalloligand as the reaction precursor is a more efficient and controllable approach to construct MMPs. Further, the metalloligand can bring multiple phosphonate groups as coordination donors with different orientations, resulting in MMPs with new structure types and special functions such as polarity. Moreover, the immobilized metalloligand with magnetic, optical, and catalytic properties can offer additional functions of MMPs for potential applications.

Given the limited types of known metallo-phosphonate ligands, the limited number of MMPs and the limited studies on their properties, the development of this field is still in its early stage.

Future challenges remain in several aspects. First, the exploration of new MMPs. This exploration can be based on the known phosphonate-based metalloligands. For example, the assembly of paddlewheel diruthenium diphosphonate with transition metal ions or clusters has not been investigated. For metalloligands based on polyazamacrocycles, the numbers of MMPs and the structural types are still very limited. Even less has been studied for metalloporphyrin and metallo-trisbipyridine-phosphonate ligands. So there is plenty of room for these already known metalloligands to construct new MMPs by optimizing reaction conditions and introducing different metal ions or clusters as nodes. The exploration of new MMPs can also be based on new phosphonate-based metalloligands by pre-design and synthesis. In this regard, there are a great many choices considering the vast reservoir of organic chelating and bridging ligands. Second, the characterization of MMPs. Metal phosphonates are well recognized by their low solubility and easy precipitation. It is often difficult to grow single crystals with sufficiently large size for conventional single crystal determination. The situation is particularly true for MMPs because the metalloligands usually possess more than one phosphonate groups which makes the solubility of MMPs even lower. Apart from the synthetic efforts to grow crystals with bigger size, a promising solution to solve the structures is by Rietveld refinement using powder X-ray diffraction data and, in some cases, combining with the single-crystal electron diffraction method. Third, the application of MMPs. The properties of MMPs originate from both the metalloligands and the second metal ions or clusters. By designing and synthesizing specific metalloligands, it is possible to construct MMPs with desired functions. For instance, the combination of paddlewheel diruthenium diphosphonate with paramagnetic transition metal ions may result in magnetic materials with long-range ordering, like that found for diruthenium phosphates. ${ }^{76}$ The MMPs containing polar metallo-polyazamacrocycles may be designed and synthesized to possess polarity or even chirality for further applications. The incorporation of luminescent cyclometalate or metal-polypyridine complexes in MMPs brings optical functions for application in sensors and multifunctional materials. By taking the advantages of metalloporphyrin, the related MMPs are expected to show interesting electrical and optical properties that can be utilized in photocatalysis and photodynamic therapy. Transformation of the channels may lead to switching in electrical and optical properties of these porphyrin-based materials. Some compounds exhibit conductance from combined mechanism such as proton conductivity together with inherent semiconducting properties, thus showing potential in multifunctional materials. Finally, the functional MMPs may be fabricated into nanoparticles, nanowires or nanosheets which may lead to applications in catalysis, molecular devices and nanotechnologies.

\section{Conflicts of interest}

There are no conflicts to declare.

\section{Acknowledgements}

Financial support from the National Natural Science Foundation of China (21731003 and 21671098) and the National Key R\&D Program of China (2018YFA0306004) is acknowledged.

\section{Notes and references}

1 (a) H. Furukawa, K. E. Cordova, M. O'Keeffe and O. M. Yaghi, Science, 2013, 341, 1230444; (b) S. Horike, S. Shimomura and S. Kitagawa, Nat. Chem., 2009, 1, 695-704; (c) W.-X. Zhang, P.-Q. Liao, R.-B. Lin, Y.-S. Wei, M.-H. Zeng and X.-M. Chen, Coord. Chem. Rev., 2015, 293-294, 263-278; (d) T. D. Bennett, A. K. Cheetham, A. H. Fuchs and F.-X. Coudert, Nat. Chem., 2017, 9, 11-16; (e) A. Kirchon, L. Feng, H. F. Drake, E. A. Joseph and H.-C. Zhou, Chem. Soc. Rev., 2018, 47, 8611-8638.

2 (a) B. B. Lin, S. C. Xiang, H. B. Xing, W. Zhou and B.-L. Chen, Coord. Chem. Rev., 2019, 378, 87-103; (b) S. Dissegna, K. Epp, W. R. Heinz, G. Kieslich and R. A. Fischer, Adv. Mater., 2018, 30, 1704501; (c) J.-G. Jia and L.-M. Zheng, Coord. Chem. Rev., 2020, 403, 213083; (d) Q. Wang and D. Astruc, Chem. Rev., 2020, 120, 1438-1511.

3 (a) Y. Cui, B. Chen and G. Qian, Coord. Chem. Rev., 2014, 273, 76-86; (b) K. Chen and C. Wu, Chin. Chem. Lett., 2018, 29, 823-826; (c) L. Zhu, X.-Q. Liu, H.-L. Jiang and L.-B. Sun, Chem. Rev., 2017, 117, 8129-8176; (d) G. M. Espallargas and E. Coronado, Chem. Soc. Rev., 2018, 47, 533-557; (e) J. Calbo, M. J. Golomb and A. Walsh, J. Mater. Chem. A, 2019, 7, 16571-16597; $(f)$ D.-W. Lim and H. Kitagawa, Chem. Rev., 2020, 120, 8416-8467.

4 (a) G. Kumar and R. Gupta, Chem. Soc. Rev., 2013, 42, 9403-9453; (b) E. Lee, S. Seo, S. S. Lee and L. F. Lindoy, Coord. Chem. Rev., 2017, 348, 121-170.

5 (a) M. C. Das, S. Xiang, Z. Zhang and B. Chen, Angew. Chem., Int. Ed., 2011, 50, 10510-10520; (b) J. Liu, L. Chen, H. Cui, J. Zhang, L. Zhang and C.-Y. Su, Chem. Soc. Rev., 2014, 43, 6011-6061; (c) M. Y. Masoomi, A. Morsali, A. Dhakshinamoorthy and H. Garcia, Angew. Chem., Int. Ed., 2019, 58, 15188-15205.

6 A. Clearfield, Progress in Inorganic Chemistry, Wiley, New York, 1998, vol. 47, pp. 371-510.

7 (a) A. D. G. Firmino, F. Figueira, J. P. C. Tomé, F. A. Almeida Paz and J. Rocha, Coord. Chem. Rev., 2018, 355, 133-149; (b) J. M. Taylor, K. W. Dawson and G. K. H. Shimizu, J. Am. Chem. Soc., 2013, 135, 1193-1196; (c) Y. Wang, J. G. Alauzun and P. H. Mutin, Chem. Mater., 2020, 32, 2910-2918.

8 (a) T. Zheng, Z. Yang, D. Gui, Z. Liu, X. Wang, X. Dai, S. Liu, L. Zhang, Y. Gao, L. Chen, D. Sheng, Y. Wang, J. Diwu, J. Wang, R. Zhou, Z. Chai, T. E. Albrecht-Schmitt and S. Wang, Nat. Commun., 2017, 8, 15369; (b) S.-B. Liu, S.-S. Bao and L.-M. Zheng, Dalton Trans., 2020, 49, 3758-3765.

9 Metal Phosphonate Chemistry: From Synthesis to Applications, ed. A. Clearfield and K. Demadis, The Royal Society of Chemistry, 2012. 
10 (a) A. Clearfield, Curr. Opin. Solid State Mater. Sci., 2002, 6, 495-506; (b) K. J. Gagnon, H. P. Perry and A. Clearfield, Chem. Rev., 2012, 112, 1034-1054; (c) W. Yang, T. G. Parker and Z.-M. Sun, Coord. Chem. Rev., 2015, 303, 86-109; (d) A. D. G. Firmino, F. Figueira, J. P. C. Tomé, F. A. Almeida Paz and J. Rocha, Coord. Chem. Rev., 2018, 355, 133-149; (e) G. Yücesan, Y. Zorlu, M. Stricker and J. Beckmann, Coord. Chem. Rev., 2018, 369, 105-122; $(f)$ G.-G. Weng and L.-M. Zheng, Sci. China: Chem., 2020, 63, 619-636; $(g)$ P. Tholen, Y. Zorlu, J. Beckmann and G. Yücesan, Eur. J. Inorg. Chem., 2020, 1542-1554.

11 J.-G. Mao, Coord. Chem. Rev., 2007, 251, 1493-1520.

12 S.-S. Bao and L.-M. Zheng, Coord. Chem. Rev., 2016, 319, 63-85.

13 S.-S. Bao, G. K. H. Shimizu and L.-M. Zheng, Coord. Chem. Rev., 2019, 378, 577-594.

14 (a) S. J. Shearan, N. Stock, F. Emmerling, J. Demel, P. A. Wright, K. D. Demadis, M. Vassaki, F. Costantino, R. Vivani, S. Sallard, I. R. Salcedo, A. Cabeza and M. Taddei, Crystals, 2019, 9, 270; (b) P. Bhanja, J. Na, T. Jing, J. Lin, T. Wakihara, A. Bhaumik and Y. Yamauchi, Chem. Mater., 2019, 31, 5343-5362.

15 (a) N. Hermer, H. Reinsch, P. Mayer and N. Stock, CrystEngComm, 2016, 18, 8147-8150; (b) T. Willhammar, Y. Yun and X. Zou, Adv. Funct. Mater., 2014, 24, 173.

16 (a) F. A. Cotton, C. A. Murillo and R. A. Walton, Multiple Bonds Between Metal Atoms, Springer Science and Business Media, New York, 3rd edn, 2005; (b) K. P. Kornecki, J. F. Berry, D. C. Powers and T. Ritter, Progress in Inorganic Chemistry, John Wiley \& Sons, Inc., 2014, vol. 58, pp. 225-302.

17 (a) H. Miyasaka, Acc. Chem. Res., 2013, 46, 248-257; (b) K. Uemura, N. Uesugi, A. Matsuyama, M. Ebihara, H. Yoshikawa and K. Awaga, Inorg. Chem., 2016, 55, 7003-7011.

18 J.-H. Yang, R.-M. Cheng, Y.-Y. Jia, J. Jin, B.-B. Yang, Z. Cao and B. Liu, Dalton Trans., 2016, 45, 2945-2954.

19 (a) F. A. Cotton, T. Datta, L. Labella and M. Shang, Inorg. Chim. Acta, 1993, 203, 55-60; (b) B.-B. Yang, L.-N. Feng, X.-M. Fan, K.-X. Zhang, J.-H. Yang and B. Liu, Inorg. Chem. Front., 2017, 4, 1061-1065.

20 X.-Y. Yi, L.-M. Zheng, W. Xu and S.-H. Feng, Inorg. Chem., 2003, 42, $2827-2829$.

21 B. Liu, Y.-Z. Li and L.-M. Zheng, Solid State Sci., 2006, 8, 1041-1045.

22 (a) X.-Y. Yi, B. Liu, R. Jiménez-Aparicio, F. A. Urbanos, S. Gao, W. Xu, J.-S. Chen, Y. Song and L.-M. Zheng, Inorg. Chem., 2005, 44, 4309-4314; (b) D. Wang, H.-Q. Yang, G.-H. Wu, X.-F. Hou, J.-H. Yang and B. Liu, Inorg. Chem. Commun., 2014, 46, 241-243.

23 B. Liu, B.-L. Li, Y.-Z. Li, Y. Chen, S.-S. Bao and L.-M. Zheng, Inorg. Chem., 2007, 46, 8524-8532.

24 S. M. Elahi, Q.-H. Lai, M. Ren, S.-S. Bao, M. Kurmoo and L.-M. Zheng, Inorg. Chem., 2019, 58, 14034-14045.

25 M. Yu Antipin, A. P. Baranov, M. I. Kabachnik, T. Ya Medved, Yu. M. Polikarpov, Yu. T. Struchkov and B. K. Shcherbakov, Dokl. Akad. Nauk SSSR, 1986, 287, 130.

26 M. I. Kabachnik, M. Yu Antipin, B. K. Shcherbakov, A. P. Baranov, Yu. T. Struchkov, T. YaMedved and Yu. M. Polikarpov, Koord. Khim., 1988, 14, 536.

27 S.-S. Bao, G.-S. Chen, Y. Wang, Y.-Z. Li, L.-M. Zheng and Q.-H. Luo, Inorg. Chem., 2006, 45, 1124-1129.

28 (a) S.-S. Bao, L.-F. Ma, Y. Wang, L. Fang, C.-J. Zhu, Y.-Z. Li and L.-M. Zheng, Chem. - Eur. J., 2007, 13, 2333-2343; (b) M. Ren, S.-S. Bao, N. Hoshino, T. Akutagawa, B. Wang, Y.-C. Ding, S. Wei and L.-M. Zheng, Chem. - Eur. J., 2013, 19, 9619-9628; (c) M. Ren, S.-S. Bao, R. A. S. Ferreira, L.-M. Zheng and L. D. Carlos, Chem. Commun., 2014, 50, 7621-7624; (d) M. Ren, C. D. S. Brites, S.-S. Bao, R. A. S. Ferreira and L.-M. Zheng, J. Mater. Chem. C, 2015, 3, 8480-8484; (e) M. Ren, S.-S. Bao, B.-W. Wang, R. A. S. Ferreira, L.-M. Zheng and L. D. Carlos, Inorg. Chem. Front., 2015, 2, 558-566.

29 S.-B. Liu, S.-S. Bao and L.-M. Zheng, Dalton Trans., 2020, 49, 3758-3765.

30 S.-S. Bao, Y. Liao, Y.-H. Su, X. Liang, F.-C. Hu, Z. Sun, L.-M. Zheng, S. Wei, R. Alberto, Y.-Z. Li and J. Ma, Angew. Chem., Int. Ed., 2011, 50, 5504-5508.

31 S.-S. Bao, K. Otsubo, J. M. Taylor, Z. Jiang, L.-M. Zheng and H. Kitagawa, J. Am. Chem. Soc., 2014, 136, 9292-9295.

32 Y.-H. Su, S.-S. Bao and L.-M. Zheng, Inorg. Chem., 2014, 53, 6042-6047.

33 S.-S. Bao, N.-Z. Li, J. M. Taylor, Y. Shen, H. Kitagawa and L.-M. Zheng, Chem. Mater., 2015, 27, 8116-8125.
34 S.-S. Bao, Y.-X. Wu, N.-Z. Li and L.-M. Zheng, Eur. J. Inorg. Chem., 2016, 4476-4482.

35 S.-B. Liu, X.-D. Huang, S.-S. Bao, M. Kurmoo and L.-M. Zheng, Cryst. Growth Des., 2019, 19, 4836-4843.

36 (a) M. P. C. Campello, S. Lacerda, I. C. Santos, G. A. Pereira, C. F. G. C. Geraldes, J. Kotek, P. Hermann, J. Vaněk, P. Lubal, V. Kubíček, É. Tóth and I. Santos, Chem. - Eur. J., 2010, 16, 8446-8465; (b) S. Hassfjell, K. O. Kongshaug and C. Rømming, Dalton Trans., 2003, 1433-1437; (c) Z. Kotková, G. A. Pereira, K. Djanashvili, J. Kotek, J. Rudovský, P. Hermann, L. V. Elst, R. N. Muller, C. F. G. C. Geraldes, I. Lukeš and J. A. Peters, Eur. J. Inorg. Chem., 2009, 119-136; (d) R. Ševčík, J. Vaněk, R. Michalicová, P. Lubal, P. Hermann, I. C. Santos, I. Santos and M. P. C. Campello, Dalton Trans., 2016, 45, 12723-12733.

37 A. Carné-Sánchez, C. S. Bonnet, I. Imaz, J. Lorenzo, É. Tóth and D. Maspoch, J. Am. Chem. Soc., 2013, 135, 17711-17714.

38 F. Avecilla, J. A. Peters and C. F. G. C. Geraldes, Eur. J. Inorg. Chem., 2003, 4179-4186.

39 (a) T.-H. Yang, K. Zhou, S.-S. Bao, C.-J. Zhu and L.-M. Zheng, Inorg. Chem. Commun., 2008, 11, 1075-1078; (b) D. Kong, D. G. Medvedev and A. Clearfield, Inorg. Chem., 2004, 43, 7308-7314.

40 J. Aríñez-Soriano, J. Albalad, C. Vila-Parrondo, J. Pérez-Carvajal, S. Rodríguez-Hermida, A. Cabeza, J. Juanhuix, I. Imaz and D. Maspoch, Chem. Commun., 2016, 52, 7229-7232.

41 G. Giambastiani, W. Oberhauser, C. Bianchini, F. Laschi, L. Sorace, P. Brueggeller, R. Gutmann, A. Orlandini and F. Vizza, Eur. J. Inorg. Chem., 2005, 2027-2031.

42 J. Rudovský, P. Cígler, J. Kotek, P. Hermann, P. Vojtíšek, I. Lukeš, J. A. Peters, L. V. Elst and R. N. Muller, Chem. - Eur. J., 2005, 11, 2373-2384.

43 P. Vojtíšek, P. Cígler, J. Kotek, J. Rudovský, P. Hermann and I. Lukeš, Inorg. Chem., 2005, 44, 5591-5599.

44 G. Neri, M. Forster, J. J. Walsh, C. M. Robertson, T. J. Whittles, P. Farràs and A. J. Cowan, Chem. Commun., 2016, 52, 14200-14203.

45 M. Paúrová, T. David, I. Císařová, P. Lubal, P. Hermann and J. Kotek, New J. Chem., 2018, 42, 11908-11929.

46 J.-G. Mao, Z. Wang and A. Clearfield, Inorg. Chem., 2002, 41, 3713-3720.

47 Handbook of Porphyrin Science, ed. K. M. Kadish, K. M. Smith and R. Guilard, World Scientific Press, Singapore, 2010-2014.

48 (a) W.-Y. Gao, M. Chrzanowski and S. Ma, Chem. Soc. Rev., 2014, 43, 5841-5866; (b) Z. Chen, J. Liu, L. Zhang and C. Su, Acta Chim. Sin., 2019, 77, 242-252; (c) J. Chen, Y. Zhu and S. Kaskel, Angew. Chem., Int. Ed., 2020, 59, DOI: 10.1002/anie.201909880.

49 (a) D. Feng, W.-C. Chung, Z. Wei, Z.-Y. Gu, H.-L. Jiang, Y.-P. Chen, D. J. Darensbourg and H.-C. Zhou, J. Am. Chem. Soc., 2013, 135, 17105-17110; (b) T.-F. Liu, D. Feng, Y.-P. Chen, L. Zou, M. Bosch, S. Yuan, Z. Wei, S. Fordham, K. Wang and H.-C. Zhou, J. Am. Chem. Soc., 2015, 137, 413-419.

50 Y. Y. Enakieva, A. G. Bessmertnykh, Y. G. Gorbunova, C. Stern, Y. Rousselin, A. Y. Tsivadze and R. Guilard, Org. Lett., 2009, 11, $3842-3845$.

51 A. A. Sinelshchikova, S. E. Nefedov, Y. Yu. Enakieva, Y. G. Gorbunova, A. Yu. Tsivadze, K. M. Kadish, P. Chen, A. Bessmertnykh-Lemeune, C. Stern and R. Guilard, Inorg. Chem., 2013, 52, 999-1008.

52 R. I. Zubatyuk, A. A. Sinelshchikova, Y. Y. Enakieva, Y. G. Gorbunova, A. Y. Tsivadze, S. E. Nefedov, A. Bessmertnykh-Lemeune, R. Guilard and O. V. Shishkin, CrystEngComm, 2014, 16, 10428-10438.

53 Y. Fang, X. Jiang, K. M. Kadish, S. E. Nefedov, G. A. Kirakosyan, Y. Y. Enakieva, Y. G. Gorbunova, A. Y. Tsivadze, C. Stern, A. Bessmertnykh-Lemeune and R. Guilard, Inorg. Chem., 2019, 58, $4665-4678$.

54 M. A. Uvarova, A. A. Sinelshchikova, M. A. Golubnichaya, S. E. Nefedov, Y. Yu. Enakieva, Y. G. Gorbunova, A. Yu. Tsivadze, C. Stern, A. Bessmertnykh-Lemeune and R. Guilard, Cryst. Growth Des., 2014, 14, 5976-5984.

55 E. V. Ermakova, Y. Yu. Enakieva, S. E. Nefedov, V. V. Arslanov, Y. G. Gorbunova, A. Yu. Tsivadze, C. Stern and A. BessmertnykhLemeune, Eur. J. Org. Chem., 2019, 3146-3162.

56 A. Yu. Mitrofanov, Y. Rousselin, V. N. Khrustalev, A. V. Cheprakov, A. Bessmertnykh-Lemeune and I. P. Beletskaya, Eur. J. Inorg. Chem., 2019, 1313-1328.

57 (a) S. E. Nefedov, K. P. Birin, A. Bessmertnykh-Lemeune, Y. Y. Enakieva, A. A. Sinelshchikova, Y. G. Gorbunova, A. Y. Tsivadze, 
C. Stern, Y. Fang and K. M. Kadish, Dalton Trans., 2019, 48, 5372-5383; (b) E. V. Vinogradova, Y. Y. Enakieva, S. E. Nefedov, K. P. Birin, A. Y. Tsivadze, Y. G. Gorbunova, A. G. B. Lemeune, C. Stern and R. Guilard, Chem. - Eur. J., 2012, 18, 15092-15104.

58 Y. Y. Enakieva, M. V. Volostnykh, S. E. Nefedov, G. A. Kirakosyan, Y. G. Gorbunova, A. Y. Tsivadze, A. G. Bessmertnykh-Lemeune, C. Stern and R. Guilard, Inorg. Chem., 2017, 56, 3055-3070.

59 S. B. Ungashe, W. L. Wilson, H. E. Katz, G. R. Scheller and T. M. Putvinski, J. Am. Chem. Soc., 1992, 114, 8717-8719.

60 T. Rhauderwiek, K. Wolkersdörfer, S. Øien-Ødegaard, K.-P. Lillerud, M. Wark and N. Stock, Chem. Commun., 2018, 54, 389-392.

61 Y. Y. Enakieva, A. A. Sinelshchikova, M. S. Grigoriev, V. V. Chernyshev, K. A. Kovalenko, I. A. Stenina, A. B. Yaroslavtsev, Y. G. Gorbunova and A. Y. Tsivadze, Chem. - Eur. J., 2019, 25, 10552-10556.

62 B. Wang, T. Rhauderwiek, A. K. Inge, H. Xu, T. Yang, Z. Huang, N. Stock and X. Zou, Chem. - Eur. J., 2018, 24, 17429-17433.

63 T. Rhauderwiek, H. Zhao, P. Hirschle, M. Döblinger, B. Bueken, H. Reinsch, D. De Vos, S. Wuttke, U. Kolb and N. Stock, Chem. Sci., 2018, 9, 5467-5478.

64 M. Maares, M. M. Ayhan, K. B. Yu, A. O. Yazaydin, K. Harmandar, H. Haase, J. Beckmann, Y. Zorlu and G. Yücesan, Chem. - Eur. J., 2019, 25, 11214-11217.

65 (a) D. Zeng, M. Ren, S.-S. Bao, L. Li and L.-M. Zheng, Chem. Commun., 2014, 50, 8356-8359; (b) D. Zeng, K. Fan, L.-P. Wang, S.S. Bao, M. Ren and L.-M. Zheng, J. Magn. Magn. Mater., 2019, 484, 139-145.
66 A. Kobayashi, K. Shimizu, A. Watanabe, Y. Nagao, N. Yoshimura, M. Yoshida and M. Kato, Inorg. Chem., 2019, 58, 2413-2421.

67 C. Köhler and E. Rentschler, Dalton Trans., 2016, 45, 12854-12861. 68 (a) F. A. Cotton, V. M. Miskowski and B. Zhong, J. Am. Chem. Soc., 1989, 111, 6177; (b) G. J. Norman, G. E. Renzoni and D. A. Case, J. Am. Chem. Soc., 1979, 101, 5256.

69 (a) D. N. Woodruff, R. E. P. Winpenny and R. A. Layfield, Chem. Rev., 2013, 113, 5110-5148; (b) Y.-S. Meng, S.-D. Jiang, B.-W. Wang and S. Gao, Acc. Chem. Res., 2016, 49, 2381-2389; (c) H. Tian and L.-M. Zheng, Acta Chim. Sin., 2020, 78, 34-55.

70 K. D. Kreuer, S. J. Paddison, E. Spohr and M. Schuster, Chem. Rev., 2004, 104, 4637-4678.

71 (a) M. M. Pereira, L. D. Dias and M. J. F. Calvete, ACS Catal., 2018, 8, 10784-10808; (b) C. F. Pereira, M. M. Q. Simões, J. P. C. Tomé and F. A. A. Paz, Molecules, 2016, 21, 1348; (c) S. Nakagaki, G. K. B. Ferreira, G. M. Ucoski and K. A. D. de Freitas Castro, Molecules, 2013, 18, 7279-7308.

72 D. Demand, B. Schollorn, D. Mansuy, J. Rouxel, P. Battioni and B. Bujoli, Chem. Mater., 1995, 7, 995-1000.

73 D. Deniaud, G. A. Spyroulias, J.-F. Bartoli, P. Battioni, D. Mansuy, C. Pinel, F. Odobel and B. Bujoli, New J. Chem., 1998, 22, 901-905.

74 A. Hu, H. L. Ngo and W. Lin, Angew. Chem., Int. Ed., 2003, 115, 6182-6185.

75 A. Hu, H. L. Ngo and W. Lin, J. Am. Chem. Soc., 2003, 125, 11490-11491.

76 B.-B. Yang, L.-N. Feng, X.-M. Fan, K.-X. Zhang, J.-H. Yang and B. Liu, Inorg. Chem. Front., 2017, 4, 1061-1065. 